Chapman University

Chapman University Digital Commons

7-31-2019

\title{
Nuclear Magnetic Resonance Solution Structure and Functional Behavior of the Human Proton Channel
}

Monika Bayrhuber

Innokentiy Maslennikov

Witek Kwiatkowski

Alexander Sobol

Christoph Wierschem

See next page for additional authors

Follow this and additional works at: https://digitalcommons.chapman.edu/pharmacy_articles

Part of the Chemical and Pharmacologic Phenomena Commons, Hemic and Immune Systems Commons, Medical Biochemistry Commons, Medicinal and Pharmaceutical Chemistry Commons, and the Other Pharmacy and Pharmaceutical Sciences Commons 
Authors

Monika Bayrhuber, Innokentiy Maslennikov, Witek Kwiatkowski, Alexander Sobol, Christoph Wierschem, Cédric Eichmann, Lukas Frey, and Roland Riek 


\section{Article}

NMR solution structure and functional behavior of the human proton channel

Monika Bayrhuber, Innokentiy Maslennikov, Witek Kwiatkowski, Alexander G.

Sobol, Christoph Wierschem, Cedric Eichmann, Lukas Frey, and Roland Riek

Biochemistry, Just Accepted Manuscript • DOI: 10.1021/acs.biochem.9b00471 • Publication Date (Web): 31 Jul 2019

Downloaded from pubs.acs.org on August 12, 2019

\section{Just Accepted}

"Just Accepted" manuscripts have been peer-reviewed and accepted for publication. They are posted online prior to technical editing, formatting for publication and author proofing. The American Chemical Society provides "Just Accepted" as a service to the research community to expedite the dissemination of scientific material as soon as possible after acceptance. "Just Accepted" manuscripts appear in full in PDF format accompanied by an HTML abstract. "Just Accepted" manuscripts have been fully peer reviewed, but should not be considered the official version of record. They are citable by the Digital Object Identifier (DOI®). "Just Accepted" is an optional service offered to authors. Therefore, the "Just Accepted" Web site may not include all articles that will be published in the journal. After a manuscript is technically edited and formatted, it will be removed from the "Just Accepted" Web site and published as an ASAP article. Note that technical editing may introduce minor changes to the manuscript text and/or graphics which could affect content, and all legal disclaimers and ethical guidelines that apply to the journal pertain. ACS cannot be held responsible for errors or consequences arising from the use of information contained in these "Just Accepted" manuscripts. 


\section{NMR solution structure and}

\section{functional behavior of the human}

\section{proton channel}

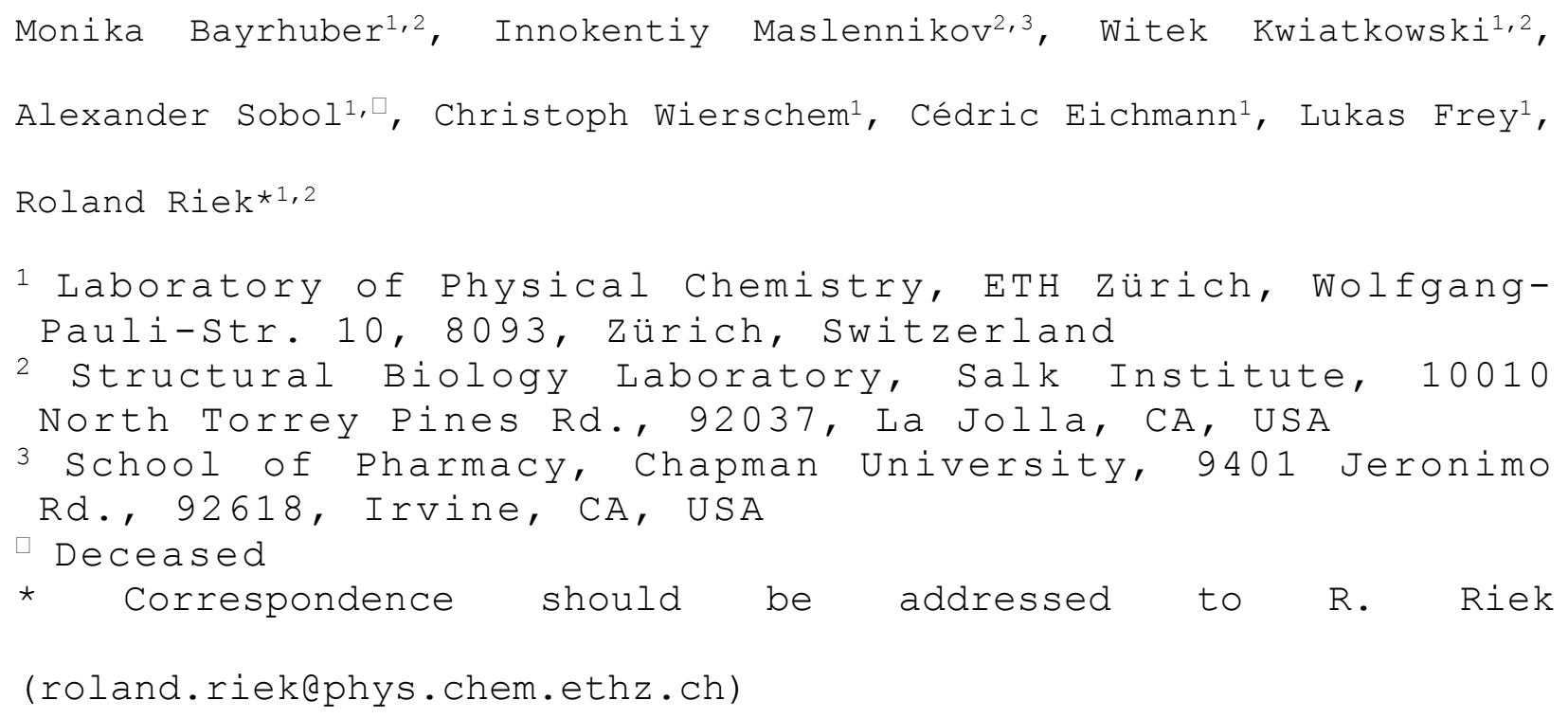




\section{ABSTRACT}

The human voltage-gated proton channel (Hvi(1) or VSDO(2)) plays an important role in the human innate immune system. Its structure differs considerably from other cation channels. It is built solely of a voltage-sensing domain and thus lacks the central pore domain, which is essential for other cation channels. Here, we determined the solution structure of an Nand C-terminal truncated human Hvl $(\Delta-H v 1)$ in the resting state by nuclear magnetic resonance (NMR) spectroscopy $\cdot \Delta-\mathrm{Hv}_{1}$ comprises the typical voltage-sensing anti-parallel four-helix bundle (S1-S4) preceded by an amphipathic helix (S0). The solution structure corresponds to an intermediate state between resting and activated forms of voltage sensing domains. Furthermore, $\mathrm{Zn}^{2+}$-induced closing of the proton channel $\Delta$-Hv1 was studied with two-dimensional NMR spectroscopy, which showed that characteristic large scale dynamics of open $\Delta$-Hvl are absent in the closed state of the channel. Additionally, pH-titration studies demonstrated that a higher $\mathrm{H}^{+}$concentration is required for the protonation of side chains in the $\mathrm{Zn}^{2+}$-induced closed state than in the open state. These observations demonstrate both structural and dynamical changes involved in the process of voltage gating of the Hvl channel and, in the future, may help 


\section{to explain the unique properties of unidirectional conductance and the exceptional ion selectivity of the channel.}




\section{INTRODUCTION}

Voltage-gated ion channels have a diverse set of biological functions. They mediate the action potential, the secretion of hormones and neurotransmitters, muscle contractions, the cortical reaction of an egg that prevents fertilization by multiple sperms, and the transpiration in a plant amongst other functions(3). The key feature of voltage gated ion channels is their ability to respond to a change in the membrane potential by opening or closing the ion permeation pathway through the cellular membrane. A special sub-class of ion channels consists of proton channels. The proton channels have been identified in snail neurons in $1982^{(4)}$ and the properties of the proton current $\left(\mathrm{G}_{\mathrm{vH}+}\right)$ have been described in detail(5, 6), but the cloning of these long sought channels had been successful only in 2006(1, 2). The voltage gated proton channel, Hv1, is found in many different species, from coccolithophores to vertebrates (7). The channel is well conserved from primitive chordates to mammals ${ }^{1}$, 2). Hvl has many important physiological roles in humans, such as triggering sperm capacitation(8) and acid extrusion in lung epithelial cells(9). It is expressed in immune cells, like granulocytes $(1,10)$ that clear organisms of bacterial pathogens by mounting a respiratory burst(11) and provides the charge compensation for this process(12, 13). However, Hv1 is also 
involved in diseases like stroke and cancer. It enhances brain damage by facilitating the production of reactive oxygen species after ischemic stroke(14). Hv1 overexpression is significantly correlated with tumor size in breast cancer(15). Furthermore, a shorter isoform of $\mathrm{Hvl}$ is specifically enriched in chronic lymphocytic leukemia cells(16) rendering Hv1 as a potential drug $\operatorname{target}^{(17)}$.

Voltage-gated cation channels, like $\mathrm{Na}^{+}, \mathrm{K}^{+}$, and $\mathrm{Ca}^{2+}$ channels, are composed of four subunits with each having six transmembrane segments (S1-S6). S5 and S6 form the hydrophilic core, while S1 to s4 constitute the voltage sensing domain $(\operatorname{VSD})(18,19)$. In response to a change in membrane potential, four VSDs modulate the conductance of the central pore domain(18, ${ }^{19)}$. The Voltage sensing is accomplished by the s4 helix, which carries the gating charges. These are positively charged amino acid residues that are placed at every third position in the helix. An outward movement of S4 leads to an opening of the pore domain, which releases ions producing the so-called alpha current (for review see Tombola $2006^{(3)}$ ). In addition to the alpha current, specific mutations within the voltage sensing domain can induce ion flow directly through this domain. For example, in shaker voltage-gated $\mathrm{K}^{+}$(20-24) and $\mathrm{Na}^{+}$channels (25, 26) 
mutations of one or more of the gating charges in $\mathrm{S} 4$ can lead to a metal cation or a proton current through the VSD, called omega or proton current, respectively. This behavior implies that the VSD alone can have an ion transfer function that is independent of the ion channel pore. The voltage-gated proton channel (Hv1(1) or $\operatorname{VSDO}^{(2)}$ ) is sufficient to reconstitute all properties of the described proton current(1, 2, 6, 13, 27-29).

In contrast to the typical voltage-gated cation channels, Hv1 contains only the VSD lacking the central pore domain(1, 2). The amino acid sequence of $\mathrm{Hvl}$ is related to the VSD of other cation channels(1, 2). Hv1 is a dimer(27, 29, 30) with each subunit comprising 273 amino acid residues. Each subunit contains both the voltage sensor and the proton pathway ${ }^{(27,29)}$. N- and Cterminal regions of the channel are required for the dimerization. Interaction between the subunits in the dimer gives rise to cooperative gating(31, 32). Nevertheless, $\mathrm{N}-$ and Cterminal truncated, monomeric versions of Hvl are still able to conduct protons ${ }^{(27,31)}$.

Mechanistically, it has been suggested that in response to membrane depolarization(32, 33), S4 moves outward followed by a distinct motion of S1 upon channel-opening(33). However, it cannot be ruled out that this movement of S1 is a direct consequence of the s4 rearrangement. 
The highly conserved aspartate D1 (Asp112 in human Hv1) is responsible for proton selectivity(34). Considering the relatively small concentration of protons compared to other cations in the physiological buffer (e.g., at pH 7, there are $10^{-7}$ M protons versus ca $0.15 \mathrm{M} \mathrm{Na}^{+}{ }^{(35)}$, this points out that this selectivity filter is extremely efficient. $\mathrm{Zn}^{2+}$ ions inhibit Hv1 by shifting the voltage threshold toward positive potentials and slowing the speed of channel opening(36), while guanidine derivatives act as open channel blockers(37).

Available atomic resolution information on $\mathrm{Hv} 1$ is based on the crystal structure of an N-terminal truncated chimera between mouse Hvl, Ciona intestinalis voltage-sensing phosphatase (CiVSP), and Saccharomyces cerevisiae transcriptional activator GCN4(38). The crystal structure of this chimera comprises the typical voltage-sensing anti-parallel four-helix bundle. Here, we present the NMR structure of the $\mathrm{N}$ - and C-terminal truncated human Hvl ( $\Delta$-Hvl) embedded in mixed detergent micelles in the presence of $\mathrm{Zn}^{2+}$ and provide $\mathrm{K}_{\mathrm{d}}$ values for $\mathrm{Zn}^{2+}$-binding and $\mathrm{pK}_{\mathrm{a}}$ values that are important for proton conductance.

\section{MATERIALS AND METHODS}

\section{a) Expression and purification of human $\Delta-\mathrm{Hv} 1$}


The human $\Delta$-Hv1 gene has 26 codons, which are rare in E. coli. Therefore, the $\Delta$-Hvl sequence was optimized for $E$. coli expression by the company GENEART, Regensburg, Germany with the program Geneoptimizer ${ }^{\circledR}$. The optimized $\Delta$-Hv1 gene was subcloned into the pET-28a vector (Novagen) containing a N-terminal Histag with a Thrombin cleavage site. The construct was transformed into E. Coli OverExpress C43(DE3) cells (Lucigen ${ }^{\circledR}$ ) for protein expression. The cells were cultured in Minimal Medium(39) at $18{ }^{\circ} \mathrm{C}$ and harvested $4 \mathrm{~d}$ after induction with $1 \mathrm{mM}$ IPTG. The cells were lysed by passing them twice through a Microfluidizer (Microfluidics, Model 110S). Inclusion bodies and cell debris were removed by centrifugation. The membrane fraction was pelleted by centrifugation at $190000 \mathrm{~g}$ for $1.5 \mathrm{~h} . \Delta$-Hv1 was extracted from the membranes with $20 \mathrm{mM}$ n-dodecylphosphocholine (FC-12) (Anatrace). The extraction mixture was cleared by centrifugation at $190000 \mathrm{~g}$ for $45 \mathrm{~min}$ and the FC-12 concentration was afterwards reduced to $10 \mathrm{~mm}$ by dilution. Nickelnitrilotriacetic acid (Ni-NTA) resin (Quiagen) was added to the solution and $\Delta-H v 1$ was allowed to bind to the resin for $16 \mathrm{~h}$. After binding the resin was washed thoroughly and $\Delta-H v 1$ was eluted with $500 \mathrm{mM}$ Imidazole in approx. 95 \% purity. The Nterminal His-Tag was removed by Thrombin (Sigma, from human 
plasma) cleavage. Thrombin was removed with BenzamidineSepharose (GE Healthcare). The cleaved His-Tag was separated from $\Delta$-Hvl by a second Ni-column. Pure $\Delta$-Hvl was eluted with $50 \mathrm{mM}$ Imidazole. For NMR measurements the buffer was exchanged by a PD-10 column (GE Healthcare) to $2 \mathrm{mM}$ lauryldimethylamine oxide (LDAO) (Fluka Analytical), $2 \mathrm{mM}$ FC-12, 20mM MES/BisTris, pH 4.7. The sample was finally concentrated to $400-800 \mu \mathrm{M} \Delta-\mathrm{Hv} 1$ and approximately $20 \mathrm{mM}$ LDAO and $20 \mathrm{mM} \mathrm{FC-12.}$

\section{b) NMR spectroscopy}

The following NMR samples were produced: [U-99\%- ${ }^{15} \mathrm{~N} ; 50-\frac{\circ}{0}-$ $\left.{ }^{2} \mathrm{H}\right]$-human $\Delta-\mathrm{Hv} 1, \quad\left[\mathrm{U}-99 \circ{ }^{13} \mathrm{C},{ }^{15} \mathrm{~N} ; \quad 50-\frac{\circ}{2}{ }^{2} \mathrm{H}\right]-$ human $\Delta-\mathrm{Hv} 1$ and $[\mathrm{U}-$ $\left.99 \div{ }^{13} \mathrm{C},{ }^{15} \mathrm{~N} ; \quad 50-\frac{\circ}{2} \mathrm{H}\right]$-human $\Delta-\mathrm{Hv} 1$ in $\left[\mathrm{U}-99 \div-{ }^{2} \mathrm{H}\right]-\mathrm{LDAO}$ and [U-99\%- $\left.{ }^{2} \mathrm{H}\right]-$ FC-12. Deuterated LDAO was purchased from FB Reagents, Cambridge, MA.

The NMR experiments were recorded at $37{ }^{\circ} \mathrm{C}$ on Bruker 600, 700, and $900 \mathrm{MHz}$ spectrometers equipped with a cryogenic probes. The following experiments were recorded: $2 \mathrm{D}\left[{ }^{15} \mathrm{~N},{ }^{1} \mathrm{H}\right]-\mathrm{TROSY}$, 3D TROSY-HNCA, 3D TROSY-MQ/CRINEPT-HN (CO)CA, 3D TROSY-HN (CA) CB, 3D TROSY-HNCO, 3D TROSY- and HMQC-based ${ }^{15} \mathrm{~N}$-resolved $\left[{ }^{1} \mathrm{H},{ }^{1} \mathrm{H}\right]-$ NOESY ${ }^{(40)}, 3 \mathrm{D}$ Co-evolved ${ }^{15} \mathrm{~N}-$ or ${ }^{13} \mathrm{C}$-resolved $\left[{ }^{1} \mathrm{H},{ }^{1} \mathrm{H}\right]-\mathrm{NOESY}-\mathrm{HSQC}$. 
The NMR data were processed and analyzed using NMRPipe, NMRDraw ${ }^{(41)}$ and SPARKY (T. D. Goddard and D. G. Kneller, SPARKY 3, University of California, San Francisco, CA) .

\title{
c) Structure calculations
}

\author{
The program CYANA $3.97^{(42)}$ was used for structure \\ calculations. Distance restraints for structure calculations \\ were collected from the $3 \mathrm{D}{ }^{15} \mathrm{~N}-$ or ${ }^{13} \mathrm{C}$-resolved NOESY spectra. For \\ these NOESY experiments protein samples with perdeuterated LDAO \\ and FC-12 were used. Upper limit restraints were calculated from \\ cross peak intensities with CYANA. In case of strong cross peak \\ overlap these restraints were adjusted manually. In total, 749 \\ NOE contacts were assigned to proton-proton distances in the \\ protein, with 245 intra-residual, 335 sequential, 139 medium- \\ range $(|i-j|<5)$, and 30 long-range $(|i-j| \geq 5)$ contacts. \\ Dihedral angle restraints predicted from chemical shift data \\ with TALOS+(43) were included in the calculations. In total, 152 \\ dihedral angle restraints were used. Based on secondary chemical \\ shift analysis 44 hydrogen bond restraints that are \\ characteristic for a helical architecture, were included. For \\ regions with missing NMR resonance assignment hydrogen bond \\ restraints were included if the region showed a helix in the \\ crystal structure of mHvlcc(38), and if a helix was predicted by


PSIPRED(44). These were in total 41 restraints for the following hydrogen bonds Phe96-Val103, Leu111-Asp112, Ser143-Phe149, Glu153-Leu158, Asp174, Trp207-Ile212.

\section{d) Determination of $\mathrm{pK}_{\mathrm{a}}$ and $\mathrm{K}_{\mathrm{d}}$ values}

NMR Titrations with $\mathrm{ZnCl}_{2}$ and $\mathrm{NaOH}$ were performed by addition of small amounts of concentrated stock solutions to the NMR sample. $\mathrm{ZnCl}_{2}$ was dissolved in water and the $\mathrm{pH}$ of the solution was adjusted to the $\mathrm{pH}$ of the $\Delta-\mathrm{Hv} 1$ sample.

To determine the $\mathrm{pK}_{\mathrm{a}}$ value of individual amino acids 2D $\left[{ }^{15} \mathrm{~N},{ }^{1} \mathrm{H}\right]-T R O S Y$ spectra were recorded at 6 different $\mathrm{pH}$ values (with $\mathrm{Zn}^{2+}$ : $\mathrm{pH}$ 5.3, $\mathrm{pH}$ 5.7, $\mathrm{pH}$ 6.0, $\mathrm{pH}$ 6.3, $\mathrm{pH}$ 6.8, $\mathrm{pH}$ 7.3; without $\mathrm{Zn}^{2+}$ : $\mathrm{pH}$ 5.3, $\mathrm{pH}$ 5.8, $\mathrm{pH}$ 6.3, $\mathrm{pH}$ 6.8, $\mathrm{pH}$ 7.2, $\mathrm{pH}$ 7.8). The chemical shift was plotted versus the pH value. We used either the proton or the nitrogen chemical shift, depending on which nucleus showed the strongest chemical shift change during the titration. We fitted the chemical shift changes observed with the Henderson-Hasselbalch equation:

$$
f(p H)=\frac{\Delta_{\min }+\left(\Delta_{\max }-\Delta_{\min }\right)}{1+10^{\left(p K_{a}-p H\right)}}
$$

or the corresponding equation if decreasing chemical shift values were observed: 


$$
f(p H)=\frac{\Delta_{\text {min }}+\left(\Delta_{\max }-\Delta_{\min }\right)}{1+10^{\left(p H-p K_{a}\right)}}
$$

where $\Delta_{\text {min }}$ is the minimal chemical shift value, $\Delta_{\max }$ is the maximum chemical shift value $\mathrm{pH}$ is the $\mathrm{pH}$ value of the sample and $\mathrm{pK}_{a}$ is the fitted $\mathrm{pK}_{a}$ value. $\Delta_{\min }$ and $\Delta_{\max }$ were included in the fit. Fitting was done with the program IGOR Pro 5.02 .

To determine the $\mathrm{K}_{\mathrm{d}}$ value of the $\mathrm{Zn}^{2+}$ binding we recorded 2D $\left[{ }^{15} \mathrm{~N},{ }^{1} \mathrm{H}\right]-T R O S Y$ spectra at 6 different $\mathrm{ZnCl}_{2}$ concentrations (0 mM, $0.05 \mathrm{mM}, 0.25 \mathrm{mM}, 0.5 \mathrm{mM}, \quad 1 \mathrm{mM}, 10 \mathrm{mM})$. The majority of residues were in slow exchange upon $\mathrm{Zn}^{2+}$-binding. We therefore used a similar approach as Latham et al.(45). When the cross peaks for the open and $\mathrm{Zn}^{2+}$-bound closed state were assigned we determined the fraction $\Delta-H v 1$ bound $\left(f_{b}\right)$, which is the intensity of the bound cross peak divided by the sum of the intensities for the bound and the free cross peak. In case only the $\mathrm{Zn}^{2+}{ }_{-}$ bound cross peak appeared in the course of the titration, we simply used the intensity of the bound cross peak $\left(I_{b}\right)$. We plotted $f_{b}$ or $I_{b}$ versus the $\mathrm{Zn}^{2+}$ concentration and fitted with the following equation(46):

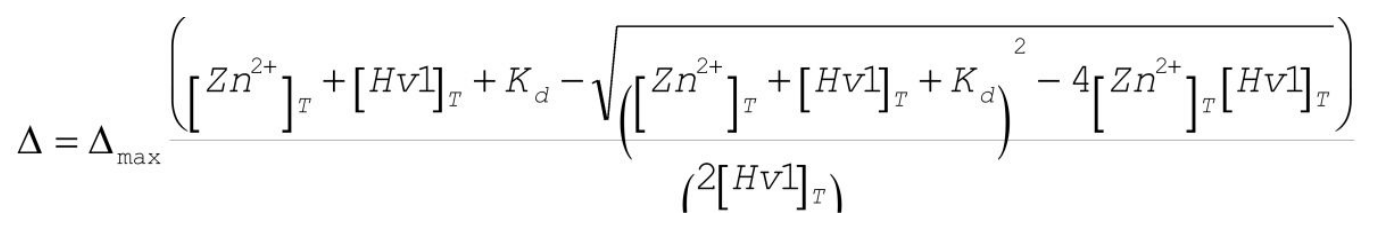


Where $\Delta$ is $f_{b}$ or $I_{b}, \Delta_{\max }$ is the respective maximum value at saturation, $\left[\mathrm{Zn}^{2+}\right]_{\mathrm{T}}$ is the total $\mathrm{ZnCl}_{2}$ concentration, [Hv1] $]_{\mathrm{T}}$ is the total $\Delta$-Hvl concentration. If possible, we used both methods to determine the $K_{d}$ value and both methods gave similar results. The fitting equation is founded on the following model: Without $\mathrm{Zn}^{2+}$ the channel is in the open state, upon $\mathrm{Zn}^{2+}$ binding, the channel is in the closed state, i.e. at $0 \mathrm{mM} \mathrm{Zn}^{2+}$ the curve should cross zero. This however was not always true for $\Delta-H_{1}$, since already without $\mathrm{Zn}^{2+}$ the channel was in equilibrium between the open and closed state. This means that without $\mathrm{Zn}^{2+}$ a cross peak at the closed position was present for some residues. In such a case we subtracted the intensity at $0 \mathrm{mM} \mathrm{Zn}^{2+}$ from all intensity values so that the curve would cross zero. This is suitable, since the $K_{d}$ value depends on the slope, not on the absolute intensity values. Again, fitting was done with the program IGOR Pro 5.02 .

\title{
RESULTS
}

\section{Sample preparation of a truncated human monomeric Hv1}

\author{
Hvl still conducts protons when the cytoplasmic $\mathrm{N}-$ and C- \\ termini are truncated ${ }^{27},{ }^{29)}$, while the truncation moves the \\ equilibrium of Hvl from a dimeric to a monomeric entity. The


truncated construct appeared to be best suitable for solutionstate NMR studies. Besides typical broadening of the NMR spectra with increasing molecular weight, the $\mathrm{N}$ - and C-terminal cytoplasmic domains gave rise to very strong peaks that overlap with the weaker signals from the transmembrane domain (data not shown). Therefore the $\mathrm{N}$ - and C-terminal truncated version of human Hv1, $\Delta$-Hv1 covering the segment from Arg83 to Arg226, was selected for further studies. As described in details in the Method section, stable isotope-labeled $\Delta$-Hv1 was overexpressed in Escherichia coli, extracted from the membranes with $n-$ dodecylphosphocholine (FC-12) and purified using Ni-NTA resin. For NMR measurements, nine different detergents and detergent mixtures were tested for the full-length Hv1. The conditions that gave the highest spectral resolution were used as a starting point for $\Delta-H v 1$ and were further modified. Finally, the protein was reconstituted in mixed detergent micelles made of lauryldimethylamine oxide (LDAO) and FC-12 in a 1:1 ratio. In some cases, detergents, including LDAO and FC-12, are known to perturb membrane protein structures(47). However, in the chosen conditions $\Delta$-Hvl binds to its antagonist $\mathrm{Zn}^{2+}$ and responds to a change in proton concentration, as a proton channel should (see 
below). Therefore, we are confident that the chosen detergent environment does not perturb the $\Delta$-Hvl structure significantly

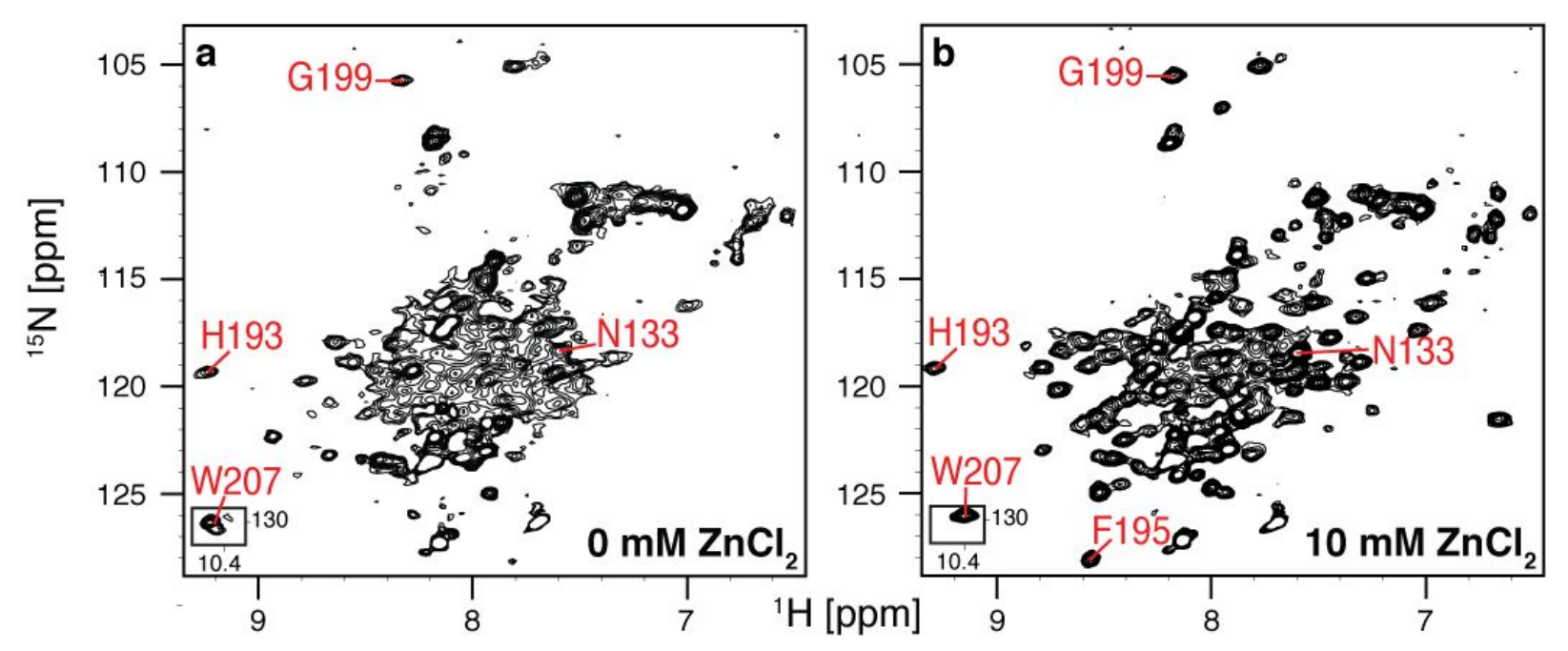

Fig. $12 \mathrm{D} \quad\left[{ }^{15} \mathrm{~N},{ }^{1} \mathrm{H}\right]-\mathrm{TROSY}$ of $0.5 \mathrm{mM} \Delta$-Hv1 in (a) the absence and (b) presence of $10 \mathrm{mM} \mathrm{ZnCl} 2$, at $\mathrm{pH} 5.8,310 \mathrm{~K}$. The presence of $10 \mathrm{mM} \mathrm{ZnCl}_{2}$ yields a much improved spectrum. The spectra were recorded on a Bruker $700 \mathrm{MHz}$ spectrometer.

An initial $\left[{ }^{15} \mathrm{~N},{ }^{1} \mathrm{H}\right]-$ TROSY spectrum of $50 \%$ deuterated ${ }^{15} \mathrm{~N}-$ labeled $\Delta$-Hv1 (Fig. 1a) shows dispersed cross peaks between 7$9.5 \mathrm{ppm}$ along the ${ }^{1} \mathrm{H}$ frequency indicative of the presence of a tertiary structure, while the broad plop around 8 ppm is attributed to the presence of conformational dynamics of the helical bundle. In order to stabilize the channel, $\mathrm{ZnCl}_{2}$ was added to induce channel closing(36). Indeed, the addition of $10 \mathrm{mM}$ $Z_{n C l}$ yielded a significantly improved NMR spectrum with sharper, 
more intense as well as new cross peaks (Fig. 1b), thus building the foundation of the structure determination by NMR.

\title{
NMR Structure Determination of Human Monomeric Hv1
}

\begin{abstract}
High field TROSY-type triple-resonance experiments were performed on a $50 \%$ deuterated ${ }^{15} \mathrm{~N},{ }^{13} \mathrm{C}-\mathrm{labeled} \Delta$-Hv1 to obtain the $70 \%$ of backbone resonance assignment. Secondary chemical shift analysis, calculated as the difference between the experimental chemical shifts and their respective random coil values, revealed the presence of five helices comprising residues Phe88Leu95 (helix S0), Cys107-Leu124 (S1), Tyr134-Met151 (S2), Phe170-Leu188 (S3) and Ala197-Val220 (S4). The presence of
\end{abstract} water-exchange cross peaks in the ${ }^{15} \mathrm{~N}$-resolved $\left[{ }^{1} \mathrm{H},{ }^{1} \mathrm{H}\right]-\mathrm{NOESY}$ spectrum (Figure S3) and overall stronger signals (typically four times stronger) for the helix so, when compared to the signals of the other helices, suggested that so can be exposed to solvent or partially attached to a membrane(38).

For the C-terminal residues from Ile213 to Arg226, two sets of cross peaks were observed. Secondary chemical shift analysis revealed that the second conformation was less helical (Figure S3). In details, secondary chemical shift values $>2$ ppm (mean $\mathrm{C} \alpha$ and $\mathrm{C}^{\prime}$ ) of at least three consecutive residues were 
considered as indicative for a helical structure. The resonances corresponded to the first conformation showed values $>2$ ppm up to residue Ile218. In turn, the signals from the second conformation showed secondary chemical shits above 2 ppm only up to residue Ile213. In addition, the secondary chemical shift values for the region Ile213 - Arg223 were always higher for the first conformation, indicating that the chemical shifts for the second conformation were closer to the random coil values. The maximal difference of the secondary chemical shifts between the first and second conformations was detected for residue Ile217. The difference gets smaller towards the N-terminal direction, where both conformations are helical, and towards the Cterminus, because both conformational states ran down into a random coil regime (Figure S3) •

There are also missing assignments comprising residues Phe96-Val103, Leu111-Asp112, Ser143-Phe149, Glu153-Leu158, Asp174, and Trp207-Ile212 (Figure S3a) as well as the side chain $\mathrm{H}^{\varepsilon}$ of all Arg residues of helix S4. The missing assignments are attributed to a diverse set of dynamics as discussed and rationalized in details below (Sup. Info. Discussion).

Distance restraints for the structure calculations were collected from 3D ${ }^{15} \mathrm{~N}-$ or ${ }^{13} \mathrm{C}$-resolved NOESY-HSQC spectra. For 
these NOESY type experiments perdeuterated LDAO and FC-12 were employed minimizing overlap between detergent signals and signals from the methyl groups of the protein. In total, 749 NOE contacts were assigned to proton-proton distances in the protein, including 30 contacts between protons separated by more than five residues in the protein sequence termed long-range restraints (Table 1$)$.

Table 1 NMR structure determination data and analysis

\begin{tabular}{|c|c|}
\hline $\begin{array}{l}\text { NMR distance and dihedral } \\
\text { constraints }\end{array}$ & \\
\hline \multicolumn{2}{|l|}{ Distance constraints } \\
\hline Total NOE & 749 \\
\hline Intra-residue $(|i-j|=0)$ & 245 \\
\hline \multicolumn{2}{|l|}{ Inter-residue } \\
\hline Sequential $(|i-j|=1)$ & 335 \\
\hline $\begin{array}{l}\text { Medium-range }(2 \leq|i-j| \leq \\
\text { 4) }\end{array}$ & 139 \\
\hline Long-range $(|i-j| \geq 5)$ & 30 \\
\hline Hydrogen bond restraints ${ }^{a}$ & 44 \\
\hline $\begin{array}{lll}\text { Additional } & \text { Hydrogen } & \text { bond } \\
\text { restraints } & & \\
\end{array}$ & 41 \\
\hline Total dihedral-angle restraints ${ }^{c}$ & 152 \\
\hline$\varphi$ & 76 \\
\hline$\psi$ & 76 \\
\hline \multicolumn{2}{|l|}{ Structure statistics } \\
\hline $\begin{array}{lll}\text { CYANA target function } & \text { (mean } \pm \\
\text { s.d.) }\left(\AA^{2}\right) & & \\
\end{array}$ & $1.83 \pm 0.16$ \\
\hline \multicolumn{2}{|l|}{ Violations (mean \pm s.d.) } \\
\hline Distance constraint $(\AA)$ & $\begin{array}{l}0.013 \\
0.001\end{array}$ \\
\hline Dihedral-angle constraints $\left({ }^{\circ}\right)$ & $\begin{array}{l}0.369 \quad \pm \\
0.046\end{array}$ \\
\hline $\begin{array}{lll}\text { Maximum } & \text { distance } & \text { constraint } \\
\text { violation } & (\AA) & \\
\end{array}$ & $0.26 \pm 0.04$ \\
\hline dihedral-angle & $2.34 \pm 0.39$ \\
\hline
\end{tabular}




\begin{tabular}{|c|c|}
\hline violation $\left({ }^{\circ}\right)$ & \\
\hline $\begin{array}{lll}\text { Deviations } & \text { from } & \text { idealized } \\
\text { geometry } & & \\
\end{array}$ & \\
\hline 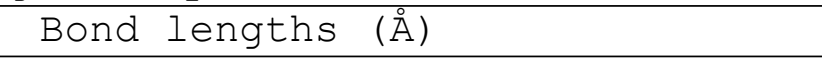 & 0.0005 \\
\hline Bond angles $\left({ }^{\circ}\right)$ & 0.04 \\
\hline $\begin{array}{ll}\text { Average } & \text { pairwise } \\
\text { deviations } & (\AA \AA \AA)\end{array}$ & \\
\hline Heavy atoms & 1.97 \\
\hline Backbone atoms & 1.38 \\
\hline Ramachandran statistics ${ }^{e}$ & \\
\hline Most favored (\%) & 81.4 \\
\hline Additionally allowed (\%) & 13.6 \\
\hline Generously allowed (\%) & 3.6 \\
\hline Disallowed (음 & 1.4 \\
\hline
\end{tabular}

a) based on NMR secondary chemical shift data

b) based on the crystal structure of mHvlcc and psipred prediction

c) dihedral angles from TALOS+(43)

d) from residue 107-153 and 172-206

e) determined by Procheck (48)

Structure calculations were performed with the program CYANA3.97(42) using NOE-based distance restraints and secondary chemical shifts-based torsion angle restraints generated by the program TALOS+(43) (Table 1). The restraints for $\alpha$-helical hydrogen bonds were included if the secondary chemical shift analysis revealed a helical structure. We also included "nonNMR" hydrogen bond restraints for regions with missing assignments (i.e., Phe96-Val103, Leu111-Asp112, Ser143-Phe149, Glu153-Leu158, Asp174, Trp207-Ile212), if the region showed an $\alpha$-helix in the crystal structure of mHvlcc(38), and if it was 
predicted to be helical by PSIPRED(44). With these restraints, a total of 100 conformers were calculated. The ensemble of ten conformers with the lowest residual CYANA target functions was taken to represent the 3D structure of $\Delta-H v 1$ (Figure 2a; the structure has been deposited in the pdb database with the code (50QK)). The 10 representative conformers of $\Delta-\mathrm{Hv} 1$ have a root mean square deviation (r.m.s.d.) of $1.44 \pm 0.35 \AA$ for the backbone atoms of residues 107-153 and 172-206, show small residual constraint violations, and small deviations from ideal geometry (Table 1). Therefore, the input data represent a selfconsistent set, and the restraints are well satisfied in the calculated representative conformers.

To investigate the structural influence of the hydrogen bonds introduced for $\Delta$-Hvl regions with missing backbone assignment, a structure was calculated without the non-NMR-based hydrogen bond restraints. Overall, both calculated structures of $\Delta$-Hv1 were similar (Figure S1). The differences were an expected increase of disorder and a tendency of helix S4 to form a kink in the absence of the non-NMR-based hydrogen bond restraints. The presence of such a flexible kink is unlikely, since the Cterminal half of the kinked helix $\mathrm{S} 4$ would be partially exposed to solvent, while the C-terminus of $\Delta$-Hv1 would partially be 
shielded from the solvent, which contradicts the water-exchange data (Figure s3e and f). Even though the presence of a kink in helix s4 is unlikely, we do observe intermediate scale dynamics between a helical and a less helical state for S4 (Sup. Info. Discussion). Therefore we consider the presented structure as the helical limit of this conformational change.

\title{
The NMR Structure of Human Monomeric Hv1
}

\author{
The solution structure of $\Delta$-Hv1 consists of an expected \\ transmembrane anti-parallel four-helix bundle (S1-S4) comprising \\ residues Cys107-Leu124 (S1), Tyr134-Met151 (S2), Phe170-Leu188 \\ (S3) and Ala197-Val220 (S4). The helices are connected by short, \\ well-defined loops. This transmembrane domain is preceded by an \\ amphipathic helix (SO) comprising residues Phe88-Leug5 that is \\ oriented perpendicular to the transmembrane domain while not \\ well defined in the lateral orientation indicating a membrane \\ surface attachment (Fig. 2). The arginine side chains on helix \\ S4, i.e., Arg205 (R1), Arg208 (R2) and Arg211 (R3), are \\ important for voltage sensing and channel gating(18) and can form \\ salt bridges with Asp112 (the selectivity filter, D1), Glul19 \\ and Asp174. Since NMR signals are missing for Asp112, Arg208, \\ and Arg211 (Sup. Info. Discussion), the side chain conformations




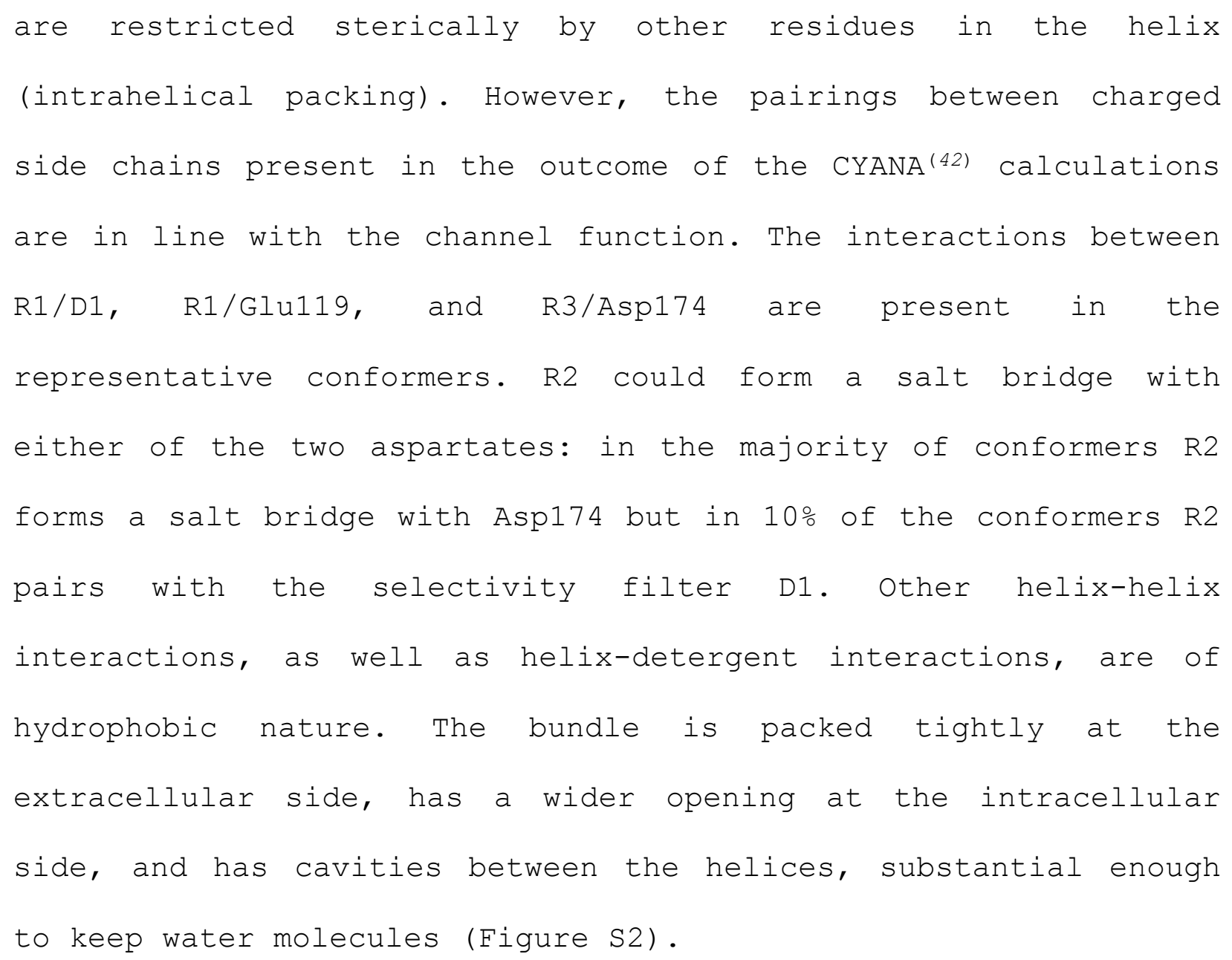




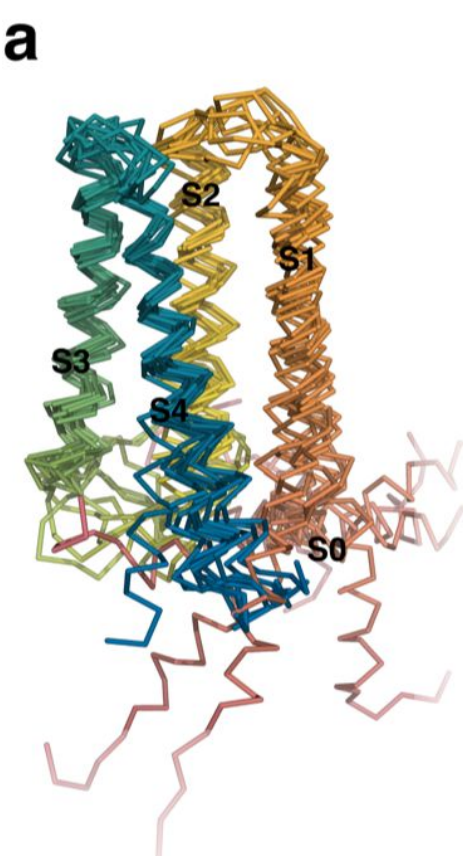

b

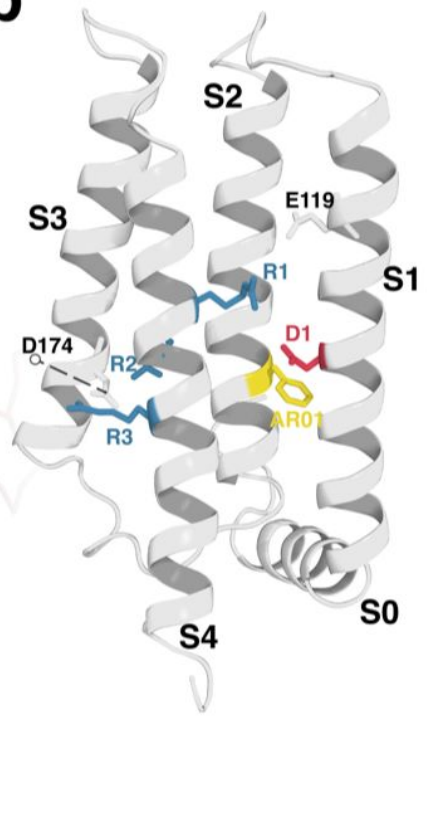

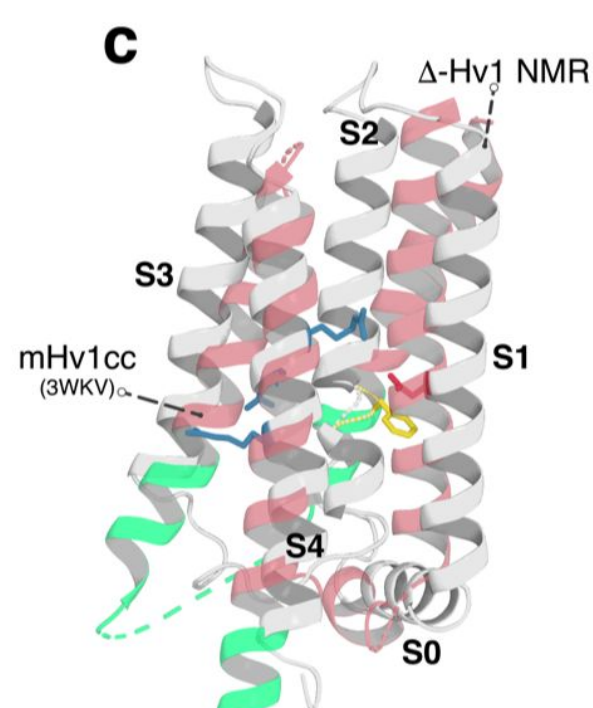

Fig. 2 a) NMR solution structure of $\Delta$-Hv1 in the closed state, due to the presence of $10 \mathrm{mM} \mathrm{ZnCl}_{2}$. The structure is represented by a superposition of the 10 conformers with the lowest CYANA target function. For each conformer the backbone trace is shown and the color changes from the N-terminus to the c-terminus from red to blue, respectively. b) Conformer with the lowest CYANA target function. Important side chains that are discussed in the text are indicated. c) Superposition of the NMR structure represented with the conformer with the lowest CYANA target function (grey) with the crystal structure of mHvlcc (pdb: 3WKV) (red/green). The parts of mouse Hvl that were exchanged to parts of Saccharomyces cerevisiae GCN4 and Ciona intestinalis VSP are shown in green. Figures of the structures were created with the program PyMOL for Mac (The PyMOL Molecular Graphics System, Version 2.0.7 Schrödinger, LLC) .

\section{Anticipated structural changes between the open and closed}

\section{states of $\Delta-\mathrm{Hv} 1$}

Addition of $\mathrm{Zn}^{2+}$ shifts the equilibrium towards the closed state of the proton channel and slows down the speed of channel 
opening(36). Thus, the effect of $\mathrm{ZnCl}_{2}$ on $\Delta-\mathrm{Hv} 1$ was studied using 2D $\left[{ }^{15} \mathrm{~N},{ }^{1} \mathrm{H}\right]-T R O S Y$ experiments. Three kinds of spectral changes were observed upon $\mathrm{ZnCl}_{2}$ titration: (i) for some $\mathrm{N}-\mathrm{H}$ moieties (exemplified for G199 in Fig. 3) the cross peak detected in the absence of $\mathrm{ZnCl}_{2}$ lost intensity with increasing amounts of $\mathrm{ZnCl}_{2}$ while a new cross peak appeared. This phenomenon is attributed to slow conformational exchange dynamics between the open and the closed state with an estimated exchange rate of slower than $190 \mathrm{~s}^{-1}$ (Table S1). (ii) At least 21 new cross peaks appeared in the spectra upon addition of $\mathrm{ZnCl}_{2}$ (exemplified by F195 in Fig. 3) supposedly due to a suppression of conformational exchange in intermediate time scale in the closed state, that broadened the signals in the open state. (iii) An increase of intensities of the cross-peaks upon $\mathrm{ZnCl}_{2}$ titration was detected as exemplified for N133 in Fig. 3. Thus, at $10 \mathrm{mM} \mathrm{Zn}^{2+}$, we found on average a doubling of the cross peak intensity, with values going up to a seven-fold increase for some signals (Figure S3b). This intensity increase was most pronounced in the regions Val116Tyr141 and Asp185-Phe195 that match well with the $\mathrm{Zn}^{2+}$ binding site reported in the crystal structure of mHvicc(38). In the nomenclature of human $\mathrm{Hv1}$, the $\mathrm{Zn}^{2+}$ binding site suggested in the crystal structure consisted of residues Glu119, Asp123, His140, 
and supposedly His193(38). However, the position of Hisl93 is uncertain in the $x$-ray structure(38), while in the NMR structure His193 is too far away from the other three coordinating residues to contribute to the same $\mathrm{Zn}^{2+}$ binding (see Discussion). The NMR data therefore rather indicate the presence of two distinct $\mathrm{Zn}^{2+}$ binding sites, which is in line with proton current and fluorescence measurements(49): one $\mathrm{Zn}^{2+}$ binding site is centered around His140 and another one around His193.

Furthermore, upon $\mathrm{Zn}^{2+}$ addition, chemical shift changes were observed in all four transmembrane helices. Chemical shifts at the flexible $\mathrm{N}$ - and C-termini were the least affected by $\mathrm{Zn}^{2+}$ addition. The chemical shift changes indicate that upon $\mathrm{Zn}^{2+}$ binding, the helical bundle undergoes a major structural rearrangement.

Next, the thermodynamics of the $\mathrm{Zn}^{2+}$ binding were analyzed. For spectral changes upon $\mathrm{Zn}^{2+}$-binding that correspond to slow exchange between conformational states, we used an approach, similar to Latham et al.(45), and examined the dependence of the $\mathrm{Zn}^{2+}$-bound fraction of $\Delta-\mathrm{Hv} 1$ on the $\mathrm{Zn}^{2+}$ concentration (see Methods). In the cases where the fractional intensity could not be determined due to a missing or unassigned cross peak in the $\mathrm{Zn}^{2+}$-free state, we analyzed the dependence of the cross peak 
intensity in $\mathrm{Zn}^{2+}$-bound state on the $\mathrm{Zn}^{2+}$ concentration. Based on $\mathrm{K}_{\mathrm{d}}$ values of the $\mathrm{Zn}^{2+}$ binding calculated for individual $\mathrm{N}-\mathrm{H}$ moieties (Table S2) and the previous suggestion of the existence of two $\mathrm{Zn}^{2+}$ binding sites(49), we distinguished between two $\mathrm{Zn}^{2+}$ binding regions in the solution NMR structure of $\Delta$-Hvi. The first region contains residues in close proximity to His140 and two other Zn-coordinating residues, Glu119 and Asp123 (A118I126). An average $K_{d}$ value of analyzable $\mathrm{N}-\mathrm{H}$ moieties in the first region is $\sim 130 \mu \mathrm{M}$ (for individual values see Table $\mathrm{S} 2$ and Figure S4). The second region includes residues that are close to His193 and located in the flexible loop S1-S2 and the loop S3-S4. The average $K_{d}$ value for analyzable $\mathrm{N}-\mathrm{H}$ moieties in the second region is $\sim 210 \mu \mathrm{M}$ that is close to the $\mathrm{K}_{\mathrm{d}}$ value of His193 (i.e., $194 \mu \mathrm{M}$ ). The $\mathrm{K}_{\mathrm{d}}$ value of analyzable residues located close to the inner vestibule was $\sim 150 \mu \mathrm{M}$. The $\mathrm{K}_{\mathrm{d}}$ values of analyzable residues in the s4 helix showed high variability, and the average $\mathrm{K}_{\mathrm{d}}$ was $\sim 170 \mu \mathrm{M}$ that is close to a mean value for the first and second regions. The average $K_{d}$ value over the whole protein, except the flexible $\mathrm{N}-$ and C-termini, was $\sim 180 \mu \mathrm{M}$. While the differences between the $K_{d}$ values can appear due to measurement uncertainties, the distinction of region-averaged $K_{d}$ values showed reasonable correlation with the solution NMR 
structure of the channel. Thus, the differences can be explained by a (at least) two-step $\mathrm{Zn}^{2+}$ binding either to independent binding sites (supposedly at Hisl40 and Hisl93 as has been inferred from proton current and fluorescence measurements(49), but was not confirmed by the crystal structure) or to the same site centered around Hisl40 with inclusion (coordination) of His193 only at higher $\mathrm{Zn}^{2+}$ concentrations.
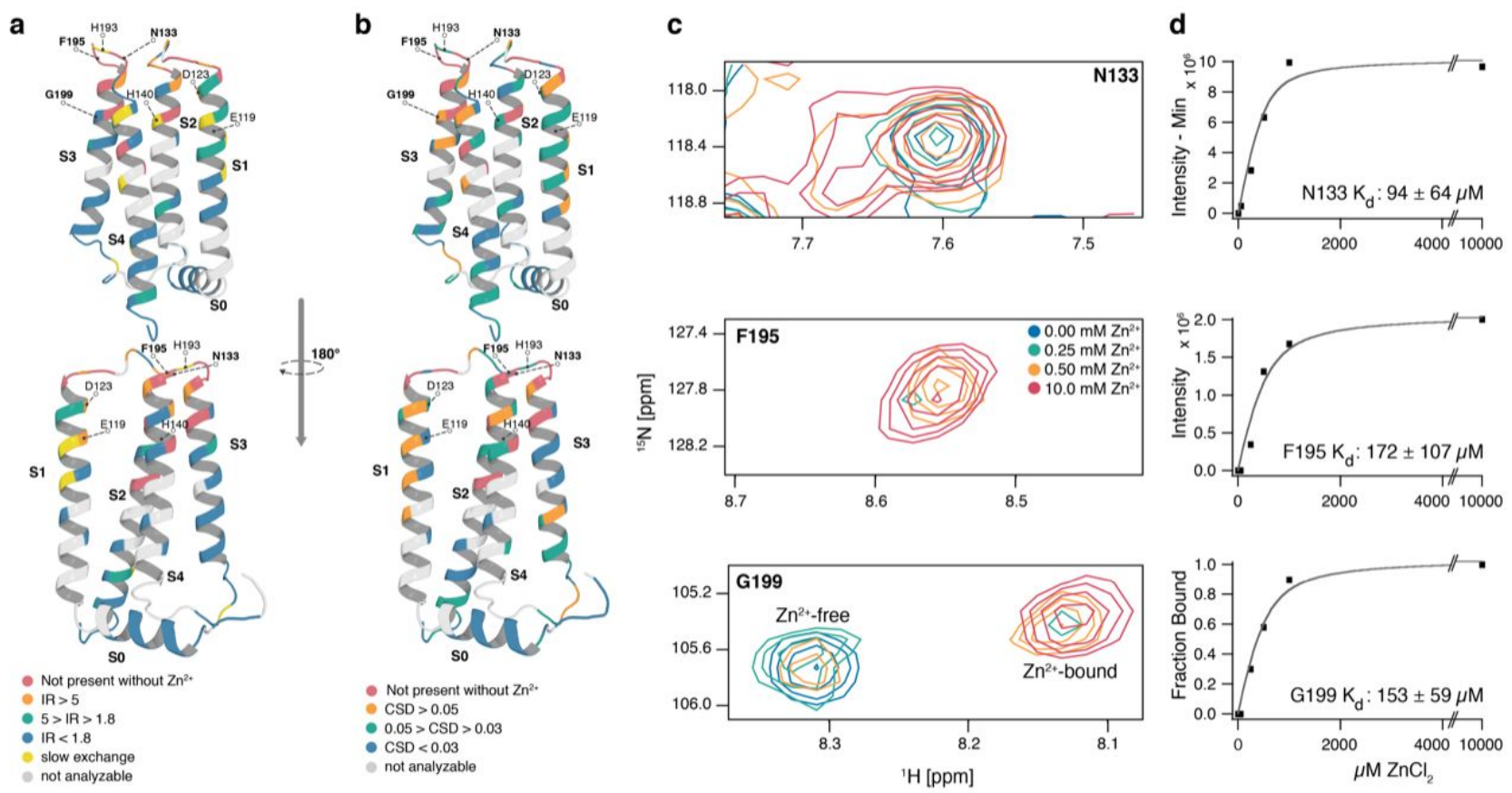

Fig. 3 Structural changes induced by closing the channel through $\mathrm{ZnCl}_{2}$ Titration. a) Intensity ratio (IR) of cross peaks in the 2D $\left[{ }^{15} \mathrm{~N},{ }^{1} \mathrm{H}\right]-\mathrm{TROSY}$ with and without $\mathrm{ZnCl}_{2}$ mapped on the NMR-structure of $\Delta$-Hvl. Red: Cross peak not present without $\mathrm{ZnCl}_{2}$, Orange: IR > 5, Green: $5>$ IR > 1.8, Blue: IR < 1.8, Yellow: Slow exchange, two peaks. Grey: not analyzable. The lower structure corresponds to the upper structure rotated by $120^{\circ}$ on a vertical axis. (Stereo view in Figure S7) b) Combined ${ }^{1} \mathrm{H}-$ and ${ }^{15} \mathrm{~N}$-chemical shift deviations $(\mathrm{CSD}) \quad(\delta \Delta(\mathrm{HN})=$ 
$\left.\left(\delta \Delta\left({ }^{1} \mathrm{H}\right)^{2}+\left(0.1 \cdot \delta \Delta\left({ }^{15} \mathrm{~N}\right)\right)^{2}\right)^{0.5}\right)$ induced by an addition of $10 \mathrm{mM} \mathrm{ZnCl}_{2}$, mapped on the NMR-structure of $\Delta$-Hv1. Red: Cross peak not present without $\mathrm{ZnCl}_{2}$, Orange: CSD > 0.05, Green: $0.05>\operatorname{CSD}>0.03$, Blue: CSD < 0.03, Grey: not analyzable. The lower structure corresponds to the upper structure rotated by $120^{\circ}$ on a vertical axis. (Stereo view in Figure S7) c) Spectral regions of the $2 \mathrm{D} \quad\left[{ }^{15} \mathrm{~N},{ }^{1} \mathrm{H}\right]-\mathrm{TROSY}$ of $\Delta-\mathrm{Hv} 1$ without $\mathrm{ZnCl}_{2}$ (blue), with $0.25 \mathrm{mM} \mathrm{ZnCl} 2$ (green), with $0.5 \mathrm{mM} \mathrm{ZnCl}_{2}$ (orange) and with $10 \mathrm{mM} \mathrm{ZnCl} 2$ (red) as indicated. For reasons of clarity, N133 was plotted with higher counter levels than F195 and G199. d) Plot representation of the cross peak intensity minus the value at $0 \mathrm{mM} \mathrm{ZnCl} 2$ versus the $\mathrm{ZnCl}_{2}$ concentration for $\mathrm{N133}$, of the cross peak intensity versus the $\mathrm{ZnCl}_{2}$ concentration for $\mathrm{F} 195$, and of the fraction bound (intensity of the bound cross peak divided by the sum of the intensities for the bound and the free cross peak) versus the $\mathrm{ZnCl}_{2}$ concentration for G199. For $\mathrm{K}_{\mathrm{d}}$ determination the data were fit using an equation for a $2^{\text {nd }}$ order reaction (see Methods).

\section{Monitoring $\mathrm{H}^{+}$ligand binding by $\mathrm{pH}$ Titration}

To get insights into the $\mathrm{H}^{+}$-ligand binding of the proton channel $\Delta$-Hv1, the pH-dependency of chemical shifts was monitored using $\left[{ }^{15} \mathrm{~N},{ }^{1} \mathrm{H}\right]-$ TROSY experiments. This monitoring is sensitive to local (de)protonation events (i.e., His, Asp, Glu) yielding individual pks and reflects both local electrostatic changes and structural rearrangements upon (de)protonation. Since protonation of the histidine side chains His140 and His193 affects $\mathrm{Zn}^{2+}$-binding, the $\mathrm{pH}$ titration was performed both in the presence and absence of $\mathrm{Zn}^{2+}$.

At $1 \mathrm{mM} \mathrm{Zn}^{2+}$ concentration and $\mathrm{pH} 5.8$, positions of all cross peaks correspond to the $\mathrm{Zn}^{2+}$-bound state, while at pH 5.3 
there is a set of minor cross peaks that represent the $\mathrm{Zn}^{2+}$-free state (Figure S5). Therefore, we assumed that lowering the pH weakened the $\mathrm{Zn}^{2+}$ binding because of the protonation of the two histidines involved (i.e., His193 and His140).

In the presence of $10 \mathrm{mM} \mathrm{Zn}^{2+}$, the perturbation of chemical shifts upon change of pH reflects fast (i.e., faster than ms) exchange between the channel states, as exemplified in Figure 4 for the four ${ }^{15} \mathrm{~N}-{ }^{1} \mathrm{H}$ moieties of Leu114 in S1, His193, G1y199 and the indole of Trp207 covering partly helix S4. Using the Henderson-Hasselbalch equation, for His193 and Gly199 pK's of 5.6 and 6.2 were determined, respectively. These pK values probably indicate the titration of $\mathrm{Zn}^{2+}$-coordinated residues His140 and His193, since the $\mathrm{pK}_{\mathrm{a}}{ }^{\prime} \mathrm{s}$ are somewhat lower or close to the $\mathrm{pK}_{\mathrm{a}}$ of a free Histidine (i.e., 6.2). The $\mathrm{pK}_{\mathrm{a}}$ value of Trp207 was 6.7, while the one of Leu114 was 5.7, respectively. The overall range of $\mathrm{pK}_{a}$ values in the $\mathrm{Zn}^{2+}$-bound channel was from below 5.5 to 7.0 (Table S3).

Next, the pH titration was performed on $\Delta$-Hv1 in the absence of $\mathrm{Zn}^{2+}$ as demonstrated again for the four residues mentioned above (Figure 4). The $\mathrm{pK}_{\mathrm{a}}{ }^{\prime} \mathrm{s}$ determined in the absence of $\mathrm{Zn}^{2+}$ for His193 and Gly199 were 6.8 and 6.2, respectively, indicating sensitivity to the protonation of the nearby 
Histidine side chains at lower $\mathrm{H}^{+}$concentrations. For Trp207, a $\mathrm{pK}_{\mathrm{a}}$ of 7.0 was observed, and for L114, a $\mathrm{pK}_{\mathrm{a}}$ of $\sim 6.7$ was measured (Figure 4). In addition, the second conformation of W207 appeared at low pH, indicating W207 sensitivity to a side chain residue with a $\mathrm{pK}_{a}$ around 6 (evaluated qualitatively). The overall range of $\mathrm{pK}_{\mathrm{a}}$ values for the channel without $\mathrm{Zn}^{2+}$ was from 6.1 to 7 .

In general, the $\mathrm{pK}_{\mathrm{a}}$ values were higher in the absence of $\mathrm{Zn}^{2+}$. This can indicate that in the absence of $\mathrm{Zn}^{2+}$ local $\mathrm{pH}$ in the channel was lower, i.e., more protons were present in the channel as is expected for an $\mathrm{H}^{+}$channel that is ready for conductance. Overall, the range of $\mathrm{pK}_{a}$ values was larger in the presence of $\mathrm{Zn}^{2+}$. This could be due to the lower $\mathrm{pK}_{\mathrm{a}}$ values of some groups participating in $\mathrm{Zn}^{2+}$-binding, or due to the observation of more diverse local protonation events, because of the fixed, closed state of the channel. In the absence of $\mathrm{Zn}^{2+}$, the channel is not fixed in one conformation so we might have seen time- and ensemble-averaged global effects upon pH change. Without $\mathrm{Zn}^{2+}$, which is the state of interest for proton channeling, ${ }^{15} \mathrm{~N}^{-1} \mathrm{H}$ signals from all residues respond to events with relatively high $\mathrm{pK}_{\mathrm{a}}$ values close to 7. This shows nicely, that within the range of physiological $\mathrm{pH}$ values, $\mathrm{H}^{+}$-ions can 
protonate the salt bridge network of $\Delta$-Hv1 and thereby are able to travel through the channel.

Without $\mathrm{Zn}^{2+}$
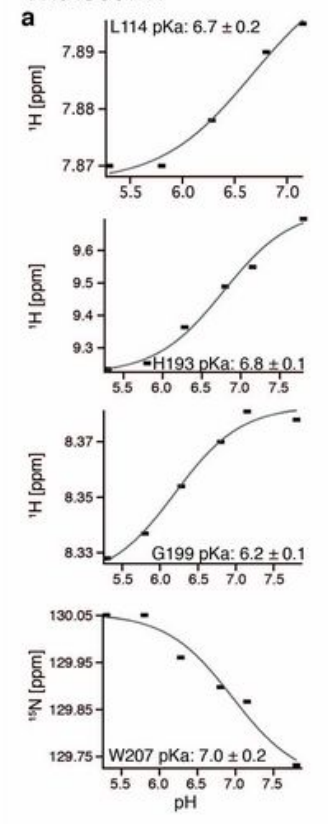

c
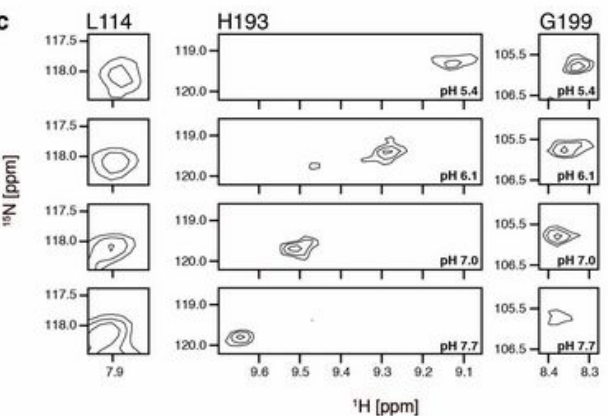

b

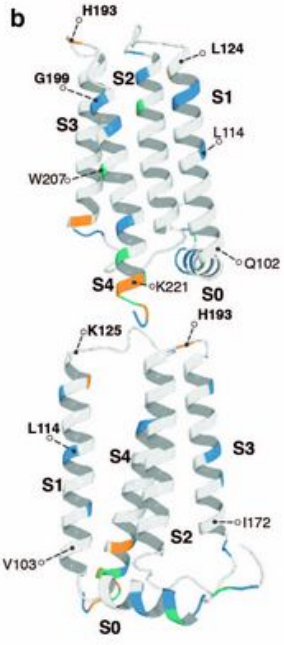

CSD $>0.15$

$0.15>$ CSD $>0.08$

CSD $<0.08$

not analyzable
With $\mathrm{Zn}^{2+}$

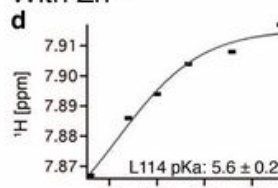

$\begin{array}{llll}5.5 & 6.0 & 6.5 & 7.0\end{array}$
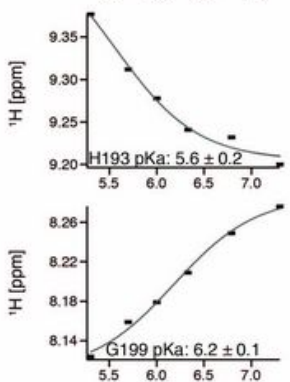

10.410- W207 pKa: $6.7 \pm 0.4$
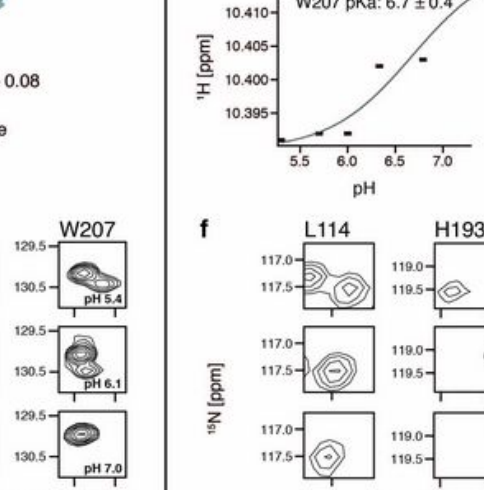

130.5-

$f$
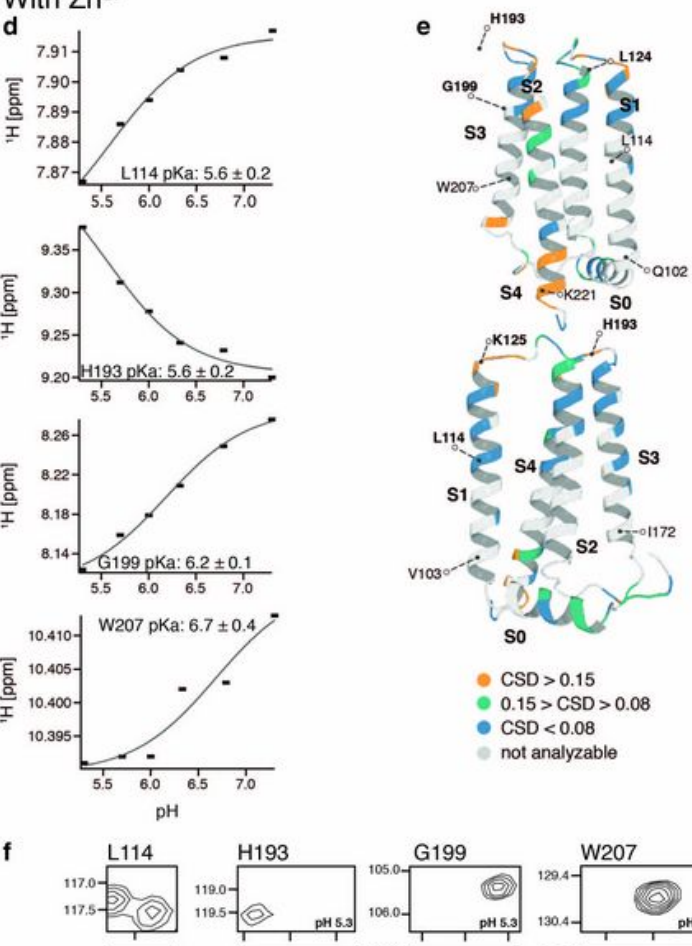

S4 20 (ख) so

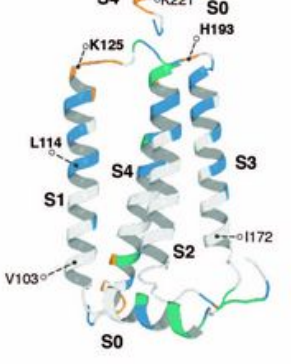

- $\mathrm{CSD}>0.15$

$0.15>\mathrm{CSD}>0.08$

- $\mathrm{CSD}<0.08$

not analyzable

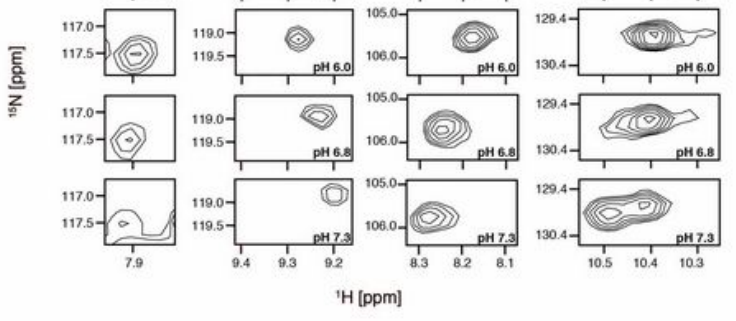

Fig. $4 \mathrm{pH}$ Titration and $\mathrm{pK}_{\mathrm{a}}$ value determination of L114, H193, G199 and W207, a, b, c without $\mathrm{Zn}^{2+}, \mathbf{d}, \mathbf{e ,} \mathbf{f}$ with $10 \mathrm{mM} \mathrm{Z \textrm {n } ^ { 2 + }}$. a, d Plot representation of the ${ }^{1} \mathrm{H}$ or ${ }^{15} \mathrm{~N}$ chemical shift versus the $\mathrm{pH}$ value. The data were fit for $\mathrm{pK}_{\mathrm{a}}$ determination using the Henderson-Hasselbalch equation. $\quad \mathbf{b}$, e Combined ${ }^{1} \mathrm{H}-$ and ${ }^{15} \mathrm{~N}-$ chemical shift deviations (CSD) $(\delta \Delta(\mathrm{HN})=$ $\left.\left(\delta \Delta\left({ }^{1} \mathrm{H}\right)^{2}+\left(0.1 \cdot \delta \Delta\left({ }^{15} \mathrm{~N}\right)\right)^{2}\right)^{0.5}\right)$ induced by a pH-jump from $\mathrm{pH} 5.3$ to 
$\mathrm{pH} 7.2$ (b), or $\mathrm{pH} 5.3$ to $\mathrm{pH} 7.3$ (e), mapped on the NMR-structure of $\Delta$-Hvl. Orange: CSD > 0.15, Green: $0.15>$ CSD > 0.08. Blue: CSD $<0.08$, Grey: not analyzable. The lower structure corresponds to the upper structure rotated by $120^{\circ}$ on a vertical axis. (Stereo view in Figure S8) c, $\mathbf{f}$ spectral regions of the 2D [15N,1H]-TROSY of $\Delta-\mathrm{Hv1}$ for L114, H193, G199 and W207 at four different pH-values: c: pH 5.4, $\mathrm{pH}$ 6.1, $\mathrm{pH}$ 7.0, $\mathrm{pH}$ 7.7; f: $\mathrm{pH}$ 5.3, $\mathrm{pH} 6.0, \mathrm{pH} 6.8, \mathrm{pH} 7.3$. The spectra were recorded on a Bruker $700 \mathrm{MHz}$ spectrometer at a temperature of $310 \mathrm{~K}$. In the beginning of the titration the sample concentration was $0.2 \mathrm{mM} \Delta-\mathrm{Hvl}$ for $\mathrm{C}$ and $0.5 \mathrm{mM} \Delta-\mathrm{Hvl}$ with $10 \mathrm{mM} \mathrm{ZnCl}_{2}$ for $\mathrm{f}$.

\section{DISCUSSION}

Comparison of the solution structure of $\Delta-H v 1$ to the crystal structures of $\mathrm{mHv} \mathrm{cc}^{(38)}$ and other voltage sensing domains

Reported X-ray structures of VSDs provide high-quality details of the proteins in static conformations, which were functionally classified as corresponding to either resting state or activated state. In contrast, the NMR structure reflects the dynamic nature of $\Delta-\mathrm{Hv} 1$ in our model system and the protein's functionally relevant responses to natural stimuli. Therefore, a comparison between the dynamic NMR structure with the static $\mathrm{X}-$ ray structures rather outlines the functional state of the NMR structure than discusses the quality or resolution of the structures.

Compared to the crystal structure of mHvlcc(38), the helices S1 and S2 are shifted down in the NMR solution structure of $\Delta^{-}$ Hv1, relative to the helices $\mathrm{S} 3$ and $\mathrm{S} 4$. While $\mathrm{s} 1$ is shifted down with respect to $\mathrm{S} 4$ by 4 to 5 residues $(\sim 6 \AA)$, S2 is shifted down 
with respect to $\mathrm{S} 3$ by 10 to 11 residues ( 16 $\AA$ ) (Figure 2c, Figure 5b and 5c). In the mHvlcc(38) construct the region from the middle of $\mathrm{s} 2$ up to the middle of $\mathrm{S3}$ was replaced with the corresponding region from Ciona intestinalis voltage sensing phosphatase (Ci-VSP; see Figure 2c). In this area, the major differences between the solution and the crystal structures occur. In addition, the NMR signals in this region of $\Delta$-Hv1 are weak or absent, indicating the presence of dynamics. It seems that the Ci-VSP loop may have stabilized a less flexible conformation prone to crystallization. Indeed, the authors of the crystal structure(38) argue, that there exist multiple resting states(50) in Hv1, as also supported by the two sets of the signals observed by NMR at the C-terminal part of helix S4 and the side chain of Trp207 in $\Delta$-Hvl. The crystal structure of mHvlcc supposedly represents an intermediate resting state(51). The structure determined by NMR at near atomic resolution (Fig. 2) is also rather in an intermediate closed state.

Comparing the $x$-ray structure with the NMR structure in details, the observed shift of $\mathrm{S} 1$ and $\mathrm{S} 2$ results in an alternate position of the gating charges with respect to the position of the highly conserved Phe150. This Phenylalanine residue is located on S2 and builds the proposed hydrophobic "cap" on the 
gating charge transfer center of voltage sensors(52) (Figure 5). We will refer to Phe150 and the corresponding aromatic residues in other voltage sensing domains as ARO1. In the NMR structure presented (Figure 5a) ARO1 is on a level between R2 and R3 (please note, that the exact side chain position of the gating charges cannot be given, since only the top and bottom of $\mathrm{S} 4$ were defined with long-range distance restraints and so only the backbone trace can be reliably given. Nevertheless, over the ensemble of ten structures with the lowest energy, the backbone trace and the side chain of ARO1 is on average closest to R2). In contrast, in the crystal structure, the backbone position of ARO1 is on the level with R1 while its side chain is between R1 and R2, pointing towards R2. In the two other resting state structures of voltage sensor domains (Ci-VSD wt(53) and AtTPC1(54) in Figures $5 e$ and d), $A R O 1$ is on the level with or slightly above R1, with no interaction between ARO1 and R2. Therefore, the crystal structure of mHvlcc appears somehow as an intermediate between the NMR structure presented and the Ci-VSP structure, which is not surprising since mHvlcc contains the Ci-VSP insert that may force mHvlcc into the Ci-VSP structure with presumably a more stable conformation in the closed state. In structures of activated voltage sensor domains (4DXW $\left.{ }^{(55)}, 2 \mathrm{R} 9 \mathrm{R}^{(56)}, 10 \mathrm{RS}{ }^{(57)}\right)$ ARO1 is usually below R3. Only in the sodium channel NavAB(58) (3RVY) 
it is slightly above R3, and in Ci-VSD R217.(53) it is on the same level as R2. Based on this comparison, the position of ARO1 relative to $\mathrm{R} 2$ in the NMR structure of $\Delta$-Hv1 corresponds to the borderline conformational state between resting and activated voltage-sensing domains. In Ci-VSP, the difference between resting (wt) and activated (R217E) states is a one helical turn

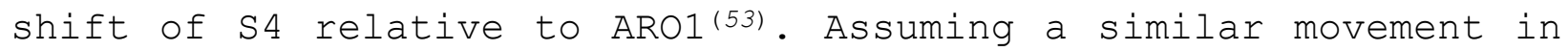
Hv1, in the supposed activated state structure of Hv1 ARO1 would be below R3, as it is observed in the majority of activated state structures. 


\title{
Resting State Structures (closed)
}

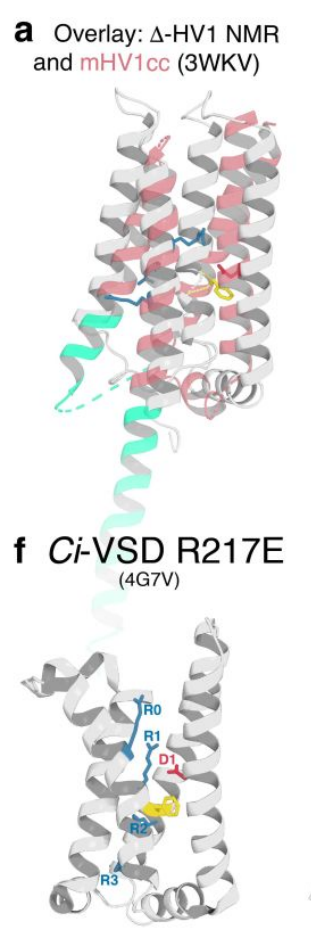

\author{
b $\Delta$-HV1 NMR
}
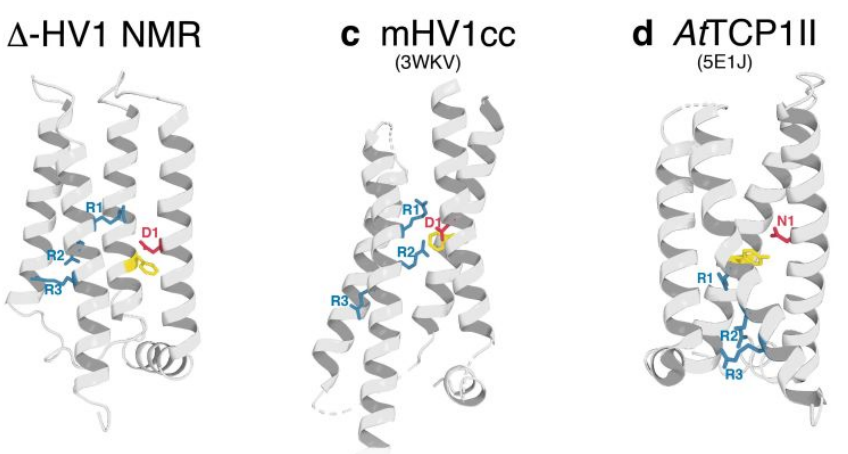

e $\underset{(4 G 8)}{C \text { VSD WT }}$

Activated State Structures (open)
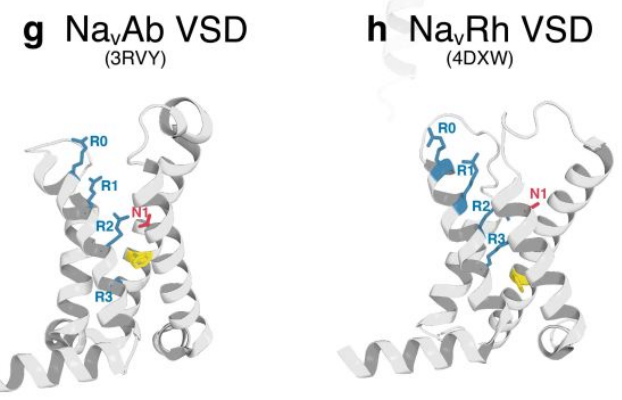

i Kv1.2-2.1 VSD
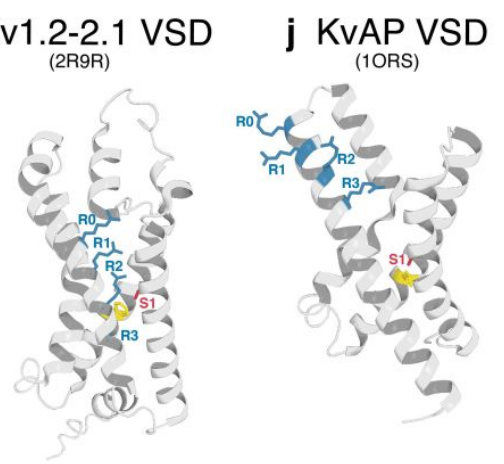

Fig. 5 Comparison of different voltage sensor domain structures in resting (a-e) and activated (f-g) state in ribbon representation. PDB codes are given in brackets. The side chains of the gating Arginies (R0-R3) are shown in blue, of the aromatic cap (ARO1) in yellow and of the selectivity filter (D1, or corresponding to that N1 or S1) in red. a) Superposition of one model of the NMR solution structure of $\Delta-H v 1$ (grey) with the crystal structure of mHV1cC (red/green). b) NMR solution structure of $\Delta-H v 1$. c) Crystal structure of the chimeric proton channel mHV1cC(38). d) Crystal structure of the voltage sensor domain II of the Arabidopsis thaliana two-pore channel 1 (AtTCPIII) ${ }^{(54)}$. e) Crystal structure of the voltage sensor domain of the wild type Ciona intestinalis voltage sensing phosphatase $(C i-V S D \text { WT })^{(53)}$. f) Crystal structure of the voltage sensor domain of the R217E mutant of Ciona intestinalis voltage sensing phosphatase (Ci-VSD R217E) (53). g) Crystal structure of the voltage sensor domain of Arcobacter butzleri voltage gated sodium channel ( $\left.\mathrm{Na}_{\mathrm{V}} \mathrm{Ab}\right)^{(58)}$. h) Crystal structure of the voltage sensor domain of alphaproteobacterium HIMB114 voltage gated sodium channel (NavRh VSD) ${ }^{(55)}$. i) Crystal structure of the 
voltage sensor domain of a chimeric voltage-dependant $\mathrm{K}^{+}$channel (KV1.2-2.1 VSD) (56). j) Crystal structure of the voltage sensor domain of the voltage-dependant $\mathrm{K}^{+}$channel from Aeropyrum pernix (KVAP VSD) (57). Figures were created with the program PyMOL for Mac (The PyMOL Molecular Graphics System, Version 2.0.7 Schrödinger, LLC).

Finally, the entirety of NMR data indicates a different model of $\mathrm{Zn}^{2+}$ binding than was suggested basing on the $\mathrm{x}-\mathrm{ray}$ structure(38). A single $\mathrm{Zn}^{2+}$ ion was identified in the electron density map(38), and among the resolved residues in the $x$-ray structure capable of $\mathrm{Zn}^{2+}$ binding, only Hisl40 was close enough to form a complex bond(38). In the x-ray structure, Glu119 and Asp123 were also close to the $\mathrm{Zn}^{2+}-$ ion but were too far away to make direct contact. These negatively charged residues were perhaps involved in coordinating water molecules around the $\mathrm{Zn}^{2+}$ ion(38). The location of His193 was not defined, but the authors

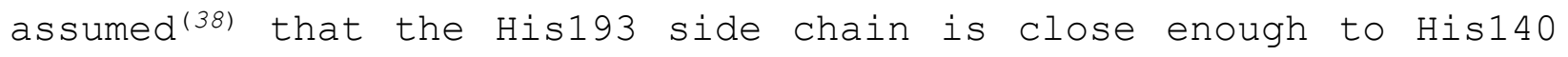
to participate in the $\mathrm{Zn}^{2+}$ binding. We added a random conformation of the missing loop containing Hislg3 into the crystal structure. In this random conformation, Hisl93 was further away from His140 than Glu119 and Asp123, which makes direct $\mathrm{Zn}^{2+}$ binding of both His140 and His193 to the same $\mathrm{Zn}^{2+}$ ion rather unlikely. In the presented NMR structure His193 is also too far away to join in a common $\mathrm{Zn}^{2+}$-coordination with Glu119, 
Asp123, and His140 (the distance between the Cys of His140 and H193 is $15.6 \pm 2.4 \AA)$. We, therefore, propose an existence of two distinct Zn ${ }^{2+}$-binding sites, one including residues Glul19, Asp123 and His140, and another around His193 including possibly E192 and E196 and perhaps 2191 and Q194. In support of this suggestion, the $\mathrm{Zn}^{2+}$ titration study showed slightly different $\mathrm{K}_{\mathrm{d}}$ values for His193 and His140 (Table S2). Electrophysiological studies also indicate the binding of two $\mathrm{Zn}^{2+}$ at two distinct $\operatorname{sites}^{(49)}$.

\section{Proton conduction of $\mathrm{Hv} 1$}

The presented NMR data support several models of proton conduction of Hvl. For example, Chamberlin et al. (59) suggest that strong interactions of a salt bridge network together with the hydrophobic cap prevent proton permeation in the closed state, while weaker interactions in the open state allow protons to pass through the channel. This is supported by the $\mathrm{pK}_{\mathrm{a}}$ values determined by NMR, which are higher in the open than in the closed, $\mathrm{Zn}^{2+}$-bound state. This means, that in the open state at physiological $\mathrm{pH}$ values, $\mathrm{H}^{+}$-ions can protonate the salt bridge network of $\Delta-H v 1$ and thereby are able to travel through the 
channel. In the closed state the side chains are not readily protonated and $\mathrm{H}^{+}-$conductance is hindered.

\section{Conclusion}

In conclusion, the NMR solution structure of an $\mathrm{N}-$ and $\mathrm{C}-$ terminal truncated version of human $\mathrm{Hvl}$ in the presence of $\mathrm{Zn}^{2+}$ in the resting state is described and accompanied with pH and $\mathrm{Zn}^{2+}$ titration studies that reveal $\mathrm{K}_{\mathrm{d}}$ and $\mathrm{pK}_{\mathrm{a}}$ values of individual residues. The presented NMR structure together with a crystal structure of a chimera of $\mathrm{Hvl}$ and the voltage sensing domain(38), which shows the electrophysiological characteristics of a proton channel, are the first atomic resolution structures of this class of proton channels. The NMR studies supported a $\mathrm{Zn}^{2+}{ }^{2}$ binding model to two independent $\mathrm{Zn}^{2+}$-binding sites. Further, the pKa values demonstrated a higher abundance of protons in the channel in the activated state and the ability of $\mathrm{H}^{+}$-ions to protonate the salt bridge network of $\Delta$-Hvl at physiological pH.

\section{Supporting Information}

Figure S1 NMR solution structure of $\Delta-\mathrm{Hv} 1$, calculated with and without not NMR-data based hydrogen bonds. 
Figure s2 Cleft analysis and water accessible surface of $\Delta$-Hv1.

Figure s3 Different NMR observables plotted versus the residue number of $\Delta-\mathrm{Hv} 1$.

Table $\mathbf{S 1}{ }^{1} \mathrm{H}$ and ${ }^{15} \mathrm{~N}$ frequency difference of cross peaks in the slow exchange regime in the $2 \mathrm{D}\left[{ }^{15} \mathrm{~N},{ }^{1} \mathrm{H}\right]-\mathrm{TROSY}$ spectra.

Table s2 $\mathrm{K}_{\mathrm{d}}$ values of $\Delta-\mathrm{Hv} 1$ binding to $\mathrm{Zn}^{2+}$ listed for individual residues.

Figure S4 Box plot with the distribution of the $\mathrm{K}_{\mathrm{d}}$ values for different groups of residues.

Table s3 $\mathrm{pK}_{a}$ values of $\Delta-\mathrm{Hv} 1$ in the presence and absence of $\mathrm{Zn}^{2+}$ listed for individual residues.

Figure s5 Spectral regions of the 2D [15N,1H]-TROSY of residue G199 of $\Delta-\mathrm{Hv} 1$ at different $\mathrm{pH}$ and $\mathrm{Zn}^{2+-c o n c e n t r a t i o n s . ~}$

Figure s6 Similar to Fig. 4 extended by data for D123, H140 and G215.

Figure 57 Stereo Views of Fig. 3a,b.

Figure s8 Stereo Views of Fig. 4b,e.

Discussion: Missing assignments.

\section{Acknowledgements}

M.B. was partly funded by the ETH Zurich Postdoctoral Fellowship Program. We thank Diego Sanchez for continuous help with protein expression. 
Competing financial interests

The authors declare no competing financial interests.

\section{Accession Code}

Hv1 Q96D96

BMRB Code

34169

References

1. Ramsey, I. S., Moran, M. M., Chong, J. A., and Clapham, D. E. (2006) A voltage-gated proton-selective channel lacking the pore domain, Nature 440, 1213-1216.

2. Sasaki, M., Takagi, M., and Okamura, Y. (2006) A voltage sensor-domain protein is a voltage-gated proton channel, Science 312, 589-592.

3. Tombola, F., Pathak, M. M., and Isacoff, E. Y. (2006) How does voltage open an ion channel?, Annual Review of Cell and Developmental Biology 22, 23-52.

4. Thomas, R. C., and Meech, R. W. (1982) Hydrogen ion currents and intracellular pH in depolarized voltage-clamped snail neurones, Nature 299, 826-828.

5. DeCoursey, T. E., Morgan, D., and Cherny, V. V. (2003) The voltage dependence of NADPH oxidase reveals why phagocytes need proton channels, Nature 422, 531-534.

6. Decoursey, T. E. (2003) Voltage-gated proton channels and other proton transfer pathways, Physiol Rev 83, 475-579.

7. Taylor, A. R., Chrachri, A., Wheeler, G., Goddard, H., and Brownlee, C. (2011) A voltage-gated $\mathrm{H}+$ channel underlying $\mathrm{pH}$ homeostasis in calcifying coccolithophores, PLoS Biol 9, e1001085.

8. Lishko, P. V., Botchkina, I. L., Fedorenko, A., and Kirichok, Y. (2010) Acid extrusion from human spermatozoa is mediated by flagellar voltage-gated proton channel, Cell 140, 327-337. 
9. Iovannisci, D., Illek, B., and Fischer, H. (2010) Function of the HVCN1 proton channel in airway epithelia and a naturally occurring mutation, M91T, J Gen Physiol 136, 35-46.

10. DeCoursey, T. E., and Cherny, V. V. (1993) Potential, pH, and arachidonate gate hydrogen ion currents in human neutrophils, Biophys $J$ 65, 1590-1598.

11. Holmes, B., Page, A. R., and Good, R. A. (1967) Studies of the metabolic activity of leukocytes from patients with a genetic abnormality of phagocytic function, J Clin Invest $46,1422-1432$.

12. Henderson, L. M., Chappell, J. B., and Jones, O. T. (1987) The superoxide-generating NADPH oxidase of human neutrophils is electrogenic and associated with an $\mathrm{H}+$ channel, Biochem J 246, 325-329.

13. Ramsey, I. S., Ruchti, E., Kaczmarek, J. S., and Clapham, D. E. (2009) Hv1 proton channels are required for high-level NADPH oxidase-dependent superoxide production during the phagocyte respiratory burst, Proceedings of the National Academy of Sciences of the United States of America 106, 7642-7647.

14. Wu, L. J., Wu, G., Akhavan Sharif, M. R., Baker, A., Jia, Y., Fahey, F. H., Luo, H. R., Feener, E. P., and Clapham, D. E. (2012) The voltage-gated proton channel Hv1 enhances brain damage from ischemic stroke, Nat Neurosci 15, 565-573.

15. Wang, Y., Li, S. J., Wu, X., Che, Y., and Li, Q. (2012) Clinicopathological and biological significance of human voltage-gated proton channel Hv1 protein overexpression in breast cancer, J Biol Chem 287, 13877-13888.

16. Hondares, E., Brown, M. A., Musset, B., Morgan, D., Cherny, V. V., Taubert, C., Bhamrah, M. K., Coe, D., Marelli-Berg, F., Gribben, J. G., Dyer, M. J., DeCoursey, T. E., and Capasso, M. (2014) Enhanced activation of an amino-terminally truncated isoform of the voltage-gated proton channel HVCN1 enriched in malignant B cells, Proc Natl Acad Sci U S A 111, 18078-18083.

17. Seredenina, T., Demaurex, N., and Krause, K. H. (2015) Voltage-Gated Proton Channels as Novel Drug Targets: From NADPH Oxidase Regulation to Sperm Biology, Antioxid Redox Signal 23, 490-513.

18. Bezanilla, F. (2000) The voltage sensor in voltage-dependent ion channels, Physiological Reviews 80, 555-592.

19. Long, S. B., Campbell, E. B., and MacKinnon, R. (2005) Voltage sensor of kv1.2: Structural basis of electromechanical coupling, Science 309, 903-908.

20. Tombola, F., Pathak, M. M., Gorostiza, P., and Isacoff, E. Y. (2007) The twisted ionpermeation pathway of a resting voltage-sensing domain, Nature 445, 546-549.

21. Tombola, F., Pathak, M. M., and Isacoff, E. Y. (2005) Voltage-sensing arginines in a potassium channel permeate and occlude cation-selective pores, Neuron 45, 379-388. 
22. Starace, D. M., and Bezanilla, F. (2001) Histidine scanning mutagenesis of basic residues of the S4 segment of the Shaker K+ channel, Journal of General Physiology 117, 469490.

23. Starace, D. M., and Bezanilla, F. (2004) A proton pore in a potassium channel voltage sensor reveals a focused electric field, Nature 427, 548-553.

24. Starace, D. M., Stefani, E., and Bezanilla, F. (1997) Voltage-dependent proton transport by the voltage sensor of the Shaker K+ channel, Neuron 19, 1319-1327.

25. Sokolov, S., Scheuer, T., and Catterall, W. A. (2005) Ion permeation through a voltagesensitive gating pore in brain sodium channels having voltage sensor mutations, Neuron 47, 183-189.

26. Sokolov, S., Scheuer, T., and Catterall, W. A. (2007) Gating pore current in an inherited ion channelopathy, Nature 446, 76-78.

27. Koch, H. P., Kurokawa, T., Okochi, Y., Sasaki, M., Okamura, Y., and Larsson, H. P. (2008) Multimeric nature of voltage-gated proton channels, Proceedings of the National Academy of Sciences of the United States of America 105, 9111-9116.

28. Musset, B., Cherny, V. V., Morgan, D., Okamura, Y., Ramsey, I. S., Clapham, D. E., and DeCoursey, T. E. (2008) Detailed comparison of expressed and native voltage-gated proton channel currents, Journal of Physiology-London 586, 2477-2486.

29. Tombola, F., Ulbrich, M. H., and Isacoff, E. Y. (2008) The voltage-gated proton channel Hv1 has two pores, each controlled by one voltage sensor, Neuron 58, 546-556.

30. Lee, S. Y., Letts, J. A., and MacKinnon, R. (2008) Dimeric subunit stoichiometry of the human voltage-dependent proton channel Hv1, Proceedings of the National Academy of Sciences of the United States of America 105, 7692-7695.

31. Tombola, F., Ulbrich, M. H., Kohout, S. C., and Isacoff, E. Y. (2010) The opening of the two pores of the Hv1 voltage-gated proton channel is tuned by cooperativity, Nat Struct Mol Biol 17, 44-50.

32. Gonzalez, C., Koch, H. P., Drum, B. M., and Larsson, H. P. (2010) Strong cooperativity between subunits in voltage-gated proton channels, Nat Struct Mol Biol 17, 51-56.

33. Mony, L., Berger, T. K., and Isacoff, E. Y. (2015) A specialized molecular motion opens the Hv1 voltage-gated proton channel, Nat Struct Mol Biol 22, 283-290.

34. Musset, B., Smith, S. M., Rajan, S., Morgan, D., Cherny, V. V., and Decoursey, T. E. (2011) Aspartate 112 is the selectivity filter of the human voltage-gated proton channel, Nature 480, 273-277.

35. DeCoursey, T. E. (2015) The Voltage-Gated Proton Channel: A Riddle, Wrapped in a Mystery, inside an Enigma, Biochemistry 54, 3250-3268.

36. Cherny, V. V., and DeCoursey, T. E. (1999) pH-dependent inhibition of voltage-gated $\mathrm{H}(+)$ currents in rat alveolar epithelial cells by $\mathrm{Zn}(2+)$ and other divalent cations, $J$ Gen Physiol 114, 819-838. 
37. Hong, L., Pathak, M. M., Kim, I. H., Ta, D., and Tombola, F. (2013) Voltage-sensing domain of voltage-gated proton channel Hvl shares mechanism of block with pore domains, Neuron 77, 274-287.

38. Takeshita, K., Sakata, S., Yamashita, E., Fujiwara, Y., Kawanabe, A., Kurokawa, T., Okochi, Y., Matsuda, M., Narita, H., Okamura, Y., and Nakagawa, A. (2014) X-ray crystal structure of voltage-gated proton channel, Nat Struct Mol Biol 21, 352-357.

39. Marley, J., Lu, M., and Bracken, C. (2001) A method for efficient isotopic labeling of recombinant proteins, J Biomol NMR 20,71-75.

40. Ying, J., Chill, J. H., Louis, J. M., and Bax, A. (2007) Mixed-time parallel evolution in multiple quantum NMR experiments: sensitivity and resolution enhancement in heteronuclear NMR, J Biomol NMR 37, 195-204.

41. Delaglio, F., Grzesiek, S., Vuister, G. W., Zhu, G., Pfeifer, J., and Bax, A. (1995) NMRPipe: a multidimensional spectral processing system based on UNIX pipes, $J$ Biomol NMR 6, 277-293.

42. Guntert, P., Mumenthaler, C., and Wuthrich, K. (1997) Torsion angle dynamics for NMR structure calculation with the new program DYANA, J Mol Biol 273, 283-298.

43. Shen, Y., Delaglio, F., Cornilescu, G., and Bax, A. (2009) TALOS+: a hybrid method for predicting protein backbone torsion angles from NMR chemical shifts, J Biomol NMR 44, 213-223.

44. Jones, D. T. (1999) Protein secondary structure prediction based on position-specific scoring matrices, J Mol Biol 292, 195-202.

45. Latham, M. P., Zimmermann, G. R., and Pardi, A. (2009) NMR chemical exchange as a probe for ligand-binding kinetics in a theophylline-binding RNA aptamer, $J$ Am Chem Soc 131, 5052-5053.

46. Cavanagh, J., Fairbrother, W. J., Palmer III, A. G., Rance, M., and Skelton, N. J. (2007) Protein NMR Spectroscopy, Principles and Practice, Second Edition ed., Elsevier.

47. Chipot, C., Dehez, F., Schnell, J. R., Zitzmann, N., Pebay-Peyroula, E., Catoire, L. J., Miroux, B., Kunji, E. R. S., Veglia, G., Cross, T. A., and Schanda, P. (2018) Perturbations of Native Membrane Protein Structure in Alkyl Phosphocholine Detergents: A Critical Assessment of NMR and Biophysical Studies, Chem Rev 118, 3559-3607.

48. Laskowski, R. A., MacArthur, M. W., Moss, D. S., and Thornton, J. M. (1993) PROCHECK - a program to check the stereochemical quality of protein structures., J App Cryst 26, 283-291.

49. Qiu, F., Chamberlin, A., Watkins, B. M., Ionescu, A., Perez, M. E., Barro-Soria, R., Gonzalez, C., Noskov, S. Y., and Larsson, H. P. (2016) Molecular mechanism of Zn2+ inhibition of a voltage-gated proton channel, Proc Natl Acad Sci U S A 113, E5962E5971. 
50. DeCoursey, T. E. (2013) Voltage-gated proton channels: molecular biology, physiology, and pathophysiology of the H(V) family, Physiol Rev 93, 599-652.

51. Delemotte, L., Tarek, M., Klein, M. L., Amaral, C., and Treptow, W. (2011) Intermediate states of the Kv1.2 voltage sensor from atomistic molecular dynamics simulations, Proc Natl Acad Sci U S A 108, 6109-6114.

52. Tao, X., Lee, A., Limapichat, W., Dougherty, D. A., and MacKinnon, R. (2010) A gating charge transfer center in voltage sensors, Science 328, 67-73.

53. Li, Q., Wanderling, S., Paduch, M., Medovoy, D., Singharoy, A., McGreevy, R., Villalba-Galea, C. A., Hulse, R. E., Roux, B., Schulten, K., Kossiakoff, A., and Perozo, E. (2014) Structural mechanism of voltage-dependent gating in an isolated voltagesensing domain, Nat Struct Mol Biol 21, 244-252.

54. Guo, J., Zeng, W., Chen, Q., Lee, C., Chen, L., Yang, Y., Cang, C., Ren, D., and Jiang, Y. (2016) Structure of the voltage-gated two-pore channel TPC1 from Arabidopsis thaliana, Nature 531, 196-201.

55. Zhang, X., Ren, W., DeCaen, P., Yan, C., Tao, X., Tang, L., Wang, J., Hasegawa, K., Kumasaka, T., He, J., Clapham, D. E., and Yan, N. (2012) Crystal structure of an orthologue of the NaChBac voltage-gated sodium channel, Nature 486, 130-134.

56. Long, S. B., Tao, X., Campbell, E. B., and MacKinnon, R. (2007) Atomic structure of a voltage-dependent $\mathrm{K}+$ channel in a lipid membrane-like environment, Nature 450, 376382.

57. Jiang, Y., Lee, A., Chen, J., Ruta, V., Cadene, M., Chait, B. T., and MacKinnon, R. (2003) X-ray structure of a voltage-dependent K+ channel, Nature 423, 33-41.

58. Payandeh, J., Gamal El-Din, T. M., Scheuer, T., Zheng, N., and Catterall, W. A. (2012) Crystal structure of a voltage-gated sodium channel in two potentially inactivated states, Nature 486, 135-139.

59. Chamberlin, A., Qiu, F., Rebolledo, S., Wang, Y., Noskov, S. Y., and Larsson, H. P. Hydrophobic plug functions as a gate in voltage-gated proton channels, Proc Natl Acad Sci US A 111, E273-282. 


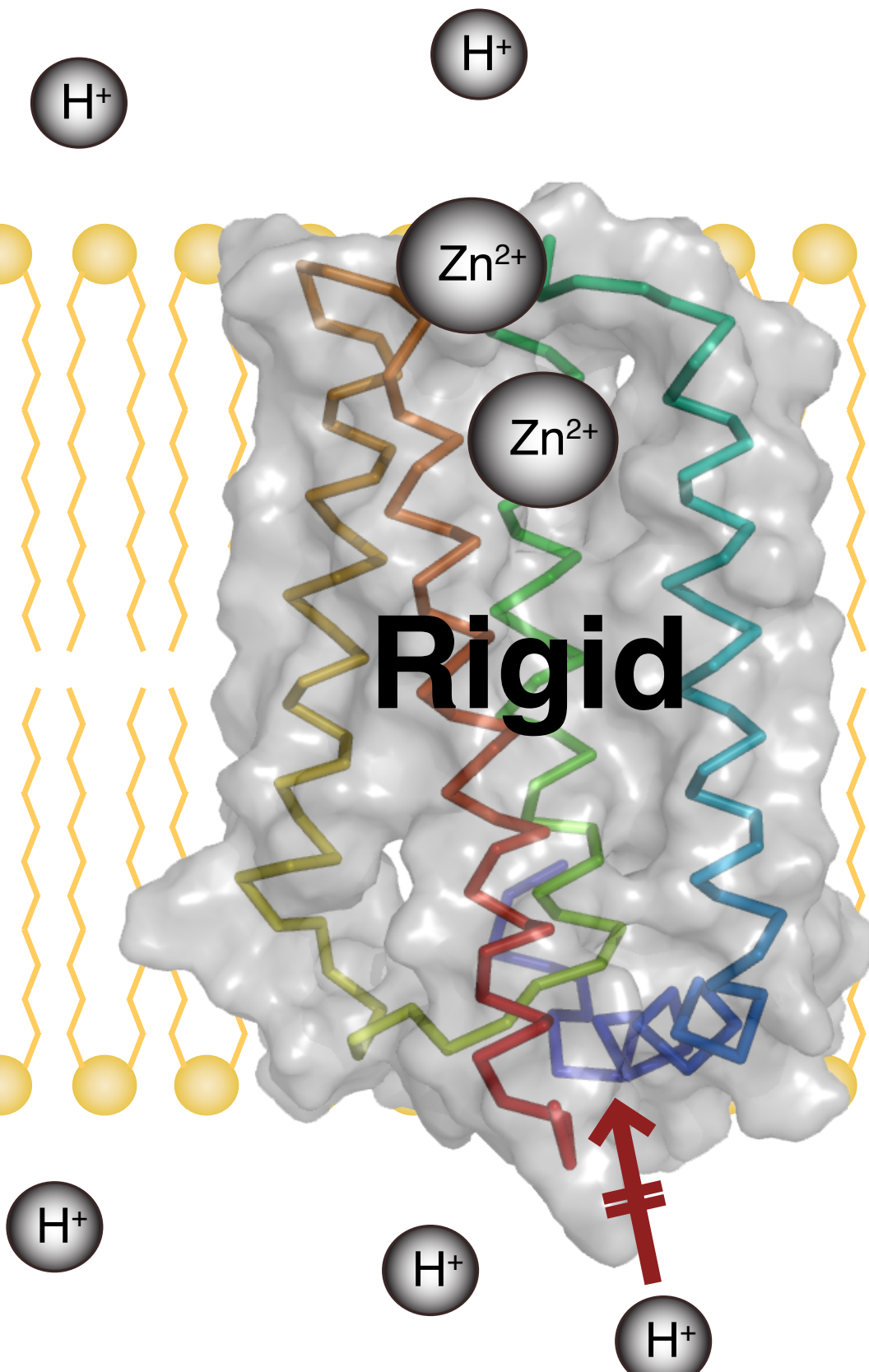

$\mathrm{H}^{+}$

(H)

(H)

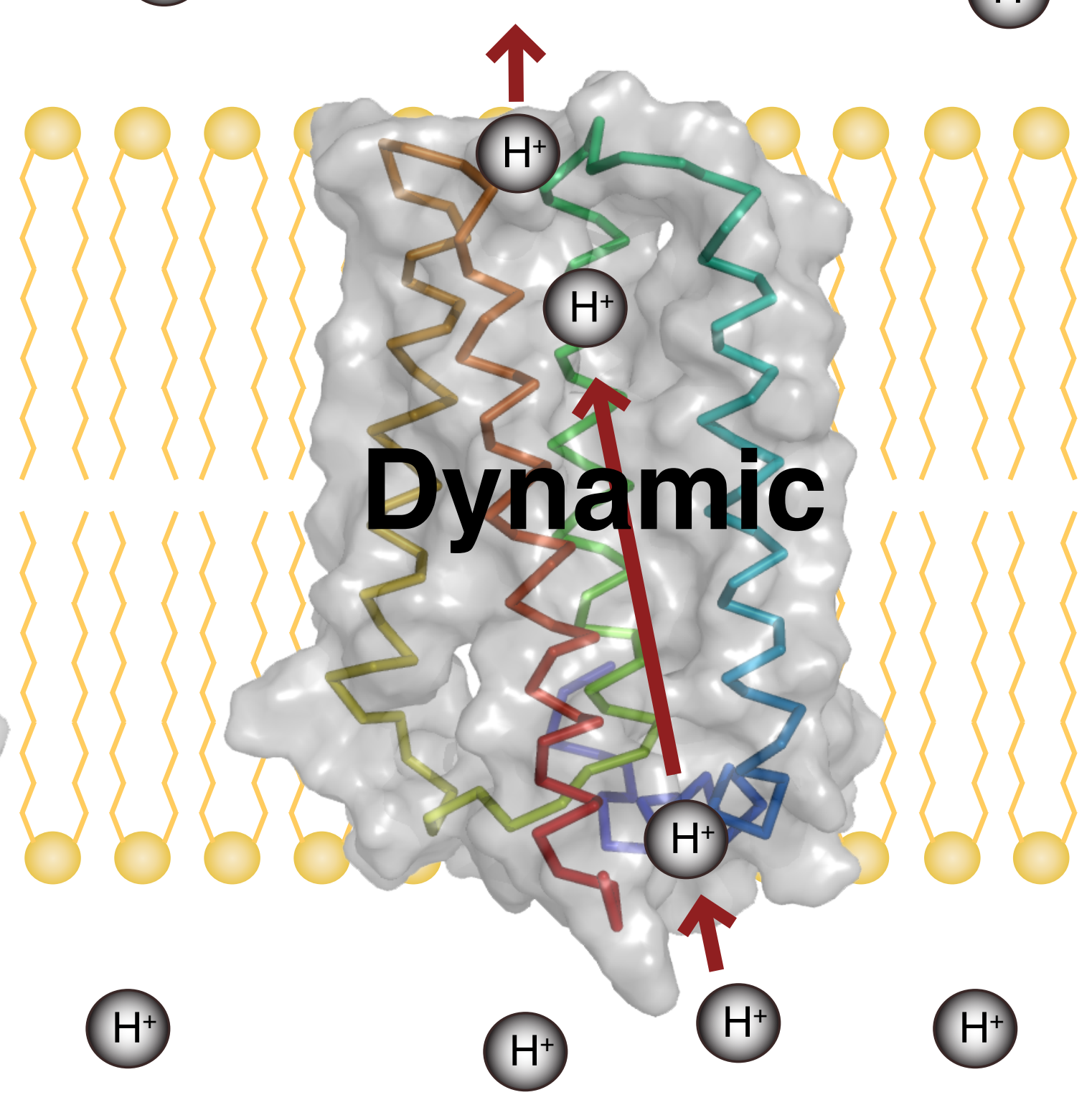

(H)

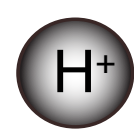

(H)

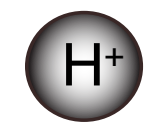

$\mathrm{H}^{+}$

$\mathrm{H}^{+}$ 